\title{
Thermally induced group effects among energy piles
}

\author{
A. F. ROTTA LORIA* and L. LALOUI*
}

\begin{abstract}
The behaviour of conventional pile groups (e.g. closely spaced) that are subjected to mechanical loads has been shown to be different from the behaviour of single isolated piles. The so-called 'group effects' are responsible for this behaviour and must be considered for an optimal design of pile foundations. In recent years, energy piles have shown potential to work as both structural supports and geothermal heat exchangers, and thus are subjected to both mechanical and thermal loads. An increasing amount of research has investigated the previously unexplored impact of thermal loads on the thermo-mechanical behaviour of energy piles. However, no field data over typical timescales of practical geothermal applications have been available to analyse the development and impact of thermally induced group effects between energy piles (e.g. closely spaced) on their thermo-mechanical behaviour. To investigate this problem, a full-scale in situ test of a group of energy piles and coupled three-dimensional thermomechanical finite-element analyses were performed and are presented in this paper. This work demonstrates that significant thermally induced group effects characterise closely spaced energy piles. Attention must be devoted to these effects throughout the design process (e.g. geotechnical, structural and energy) of energy piles because they play an important role in the serviceability performance of these foundations.
\end{abstract}

KEYWORDS: design; elasticity; finite-element modelling; in situ testing; piles \& piling; temperature effects

\section{INTRODUCTION}

Pile groups can be divided into two classes: widely and closely spaced. In widely spaced pile groups, the piles are located far enough from each other that their individual responses can be considered independent and comparable to the case of an isolated pile. In closely spaced pile groups, the piles are close enough to each other that their individual responses are influenced by the presence of and loadings on the neighbouring piles, and differ from that of an isolated pile. In the latter case, the influences between the individual pile responses of the group represent interactions (e.g. mechanical). These interactions occur between the piles, the connecting slab and the surrounding soil. They have been shown to manifest through so-called 'group effects' and to control the response of pile groups to loading. Extensive amounts of research (e.g. Poulos \& Davis, 1980; Fleming et al., 2008) have been devoted to the analysis and classification of group effects among conventional piles because of their importance for suitable designs of such foundations. Prior to this study, the analysis and classification of group effects of energy piles was preliminary and thus was considered in this work.

Energy piles represent a relatively new technology that couples the structural support role of conventional pile foundations to the role of geothermal heat exchangers to satisfy the energy needs of the building environment. In addition to the mechanical loads that are usually applied to conventional piles, thermal loads are imposed as a result of their geothermal operations.

Over the last decade, an increasing amount of research has investigated the impact of thermal loads on the thermomechanical behaviour of isolated energy piles, including a

Manuscript received 10 February 2016; revised manuscript accepted 3 October 2016. Published online ahead of print 14 November 2016. Discussion on this paper closes on 1 October 2017, for further details see p. ii.

Published with permission by the ICE under the CC-BY license. (http://creativecommons.org/licenses/by/4.0/)

* Swiss Federal Institute of Technology in Lausanne, EPFL, Laboratory of Soil Mechanics (LMS), Lausanne, Switzerland. series of full-scale in situ tests (Laloui et al., 2003; BourneWebb et al., 2009; Akrouch et al., 2014; Wang et al., 2014; Sutman et al., 2015; You et al., 2016), centrifuge (Ng et al., 2014; Stewart \& McCartney, 2014; Goode \& McCartney, 2015; $\mathrm{Ng}$ et al., 2015) and model-scale (Kalantidou et al., 2012; Kramer \& Basu, 2014; Yavari et al., 2014) experiments, and numerical analyses (Laloui et al., 2006; Suryatriyastuti et al., 2012; Mimouni \& Laloui, 2014; Olgun et al., 2014; Batini et al., 2015; Rotta Loria et al., 2015; Saggu \& Chakraborty, 2015). Several in situ tests (McCartney \& Murphy, 2012; Murphy et al., 2014; Mimouni \& Laloui, 2015) and numerical analyses (Di Donna \& Laloui, 2014; Jeong et al., 2014; Salciarini et al., 2015; Di Donna et al., 2016; Suryatriyastuti et al., 2016) have recently investigated this problem for energy pile groups. To date, however, knowledge of the development and impact of thermally induced group effects among closely spaced energy piles on their thermo-mechanical behaviour has been limited due to the lack of field data about the exploitation of energy piles that either partially or entirely operate as geothermal heat exchangers for timescales that are typical of practical applications.

To address this challenge, a full-scale in situ test of a group of closely spaced energy piles that partially operate as geothermal heat exchangers was carried out over a timescale that is typical of practical applications, and coupled threedimensional (3D) thermo-mechanical finite-element analyses were performed. The analyses and results of this experimental and numerical investigation are presented in this paper.

The paper first describes the experimental and numerical methods. The experimental and numerical results are then compared and discussed. Finally, concluding remarks which can be drawn from this work are presented.

\section{EXPERIMENTAL TESTING}

This section presents: $(a)$ the features of the experimental site; (b) the main characteristics of the testing equipment; and $(c)$ the details of the full-scale in situ test. Detailed information about the testing equipment is presented by Mimouni \& Laloui (2015). 


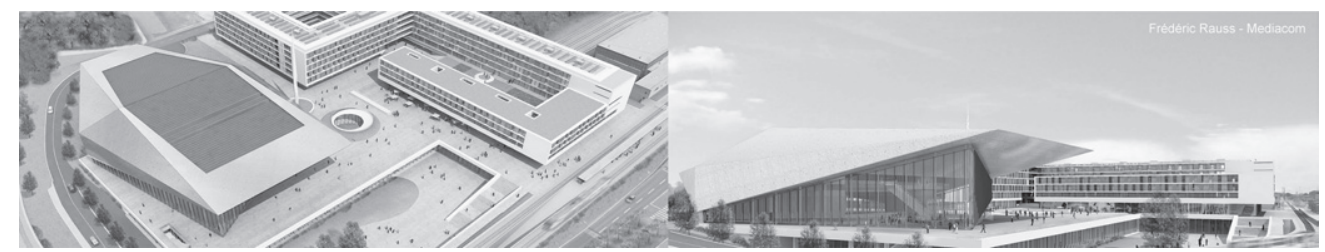

(a)

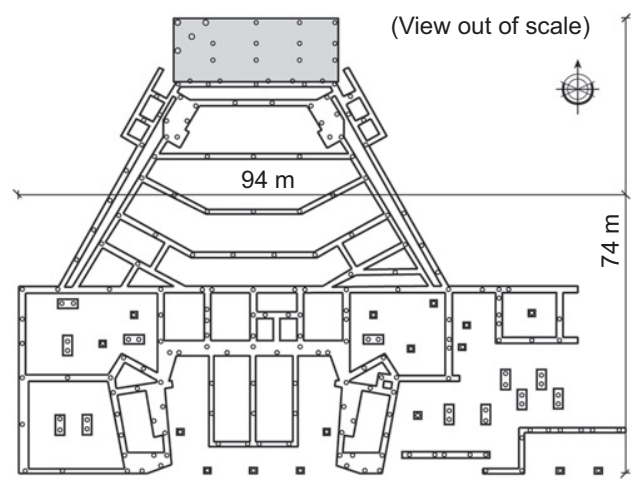

Cross-sectional plan view (out of scale) referred to $1 \mathrm{~m}$ above the uppermost surface of the slab

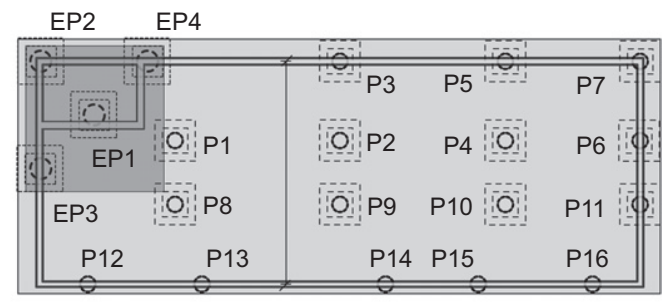

b)

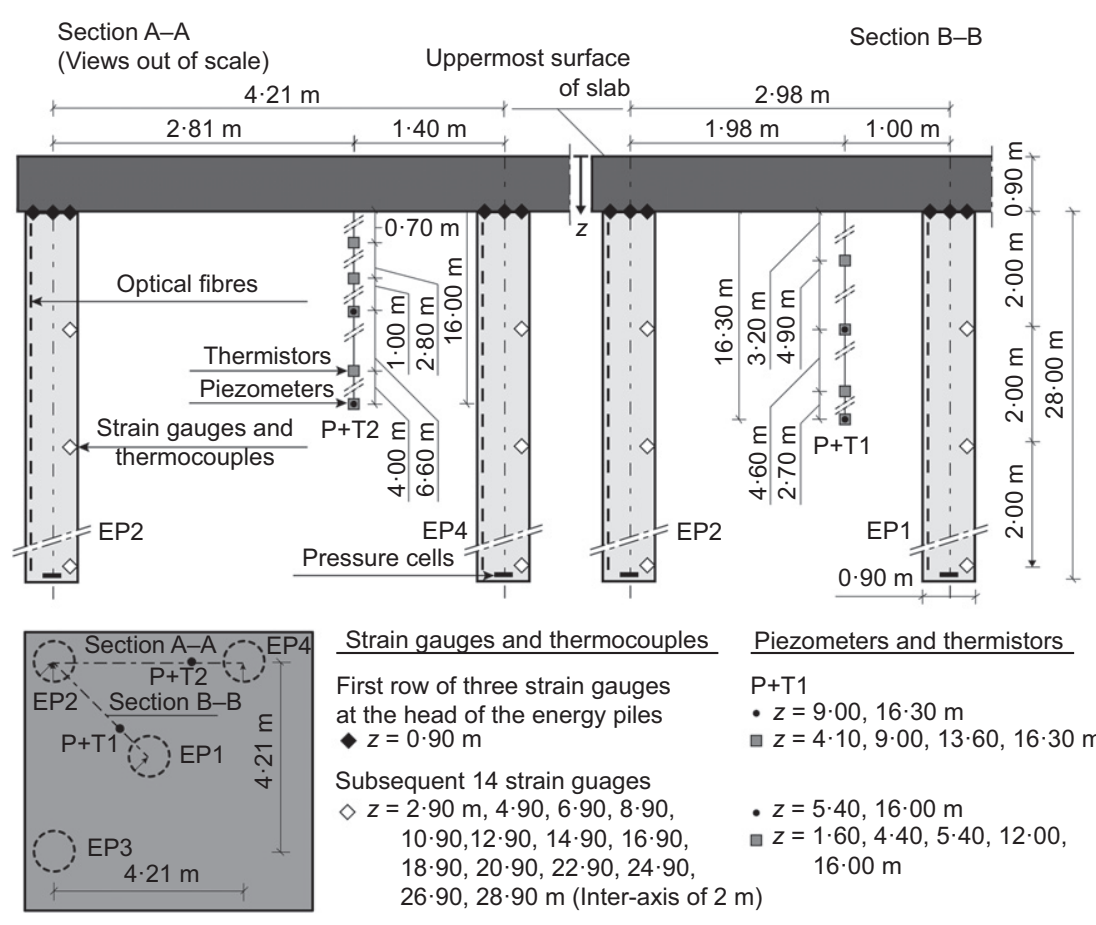

(c)

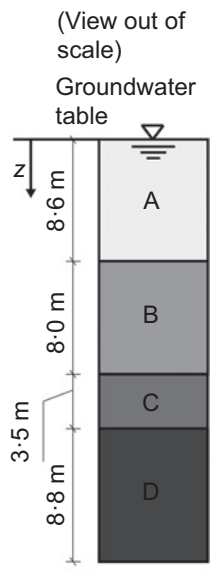

Alluvial soil - A

A $z=[0 ; 8.6] \mathrm{m}$

Sandy-gravelly

B moraine $-\mathrm{B}$

$z=[8 \cdot 6 ; 16 \cdot 6] \mathrm{m}$

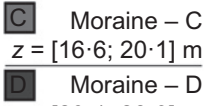

$z=[20 \cdot 1 ; 28 \cdot 9] \mathrm{m}$

(d)

Fig. 1. (a) The EPFL Swiss Tech Convention Centre (modified from the original image, courtesy of Richter Dahl Rocha \& Associés architectes SA); (b) plan view of the foundation including the four energy piles; (c) vertical cross-sections depicting the monitoring instrumentation that was installed in the energy piles and soil; (d) schematic diagram of the soil stratigraphy

\section{The pile foundation and site}

The pile foundation that was considered for the experimental test is located under the recently built Swiss Tech Convention Centre, Lausanne, Switzerland (see Fig. 1(a)). The foundation supports a $9 \times 25 \mathrm{~m}^{2}$ water retention tank and comprises a group of four end-bearing energy piles (labelled EP1, EP2, EP3 and EP4 in Fig. 1(b)) and 16 semifloating conventional piles (labelled P1-P16 in Fig. 1(b)) below a heavily reinforced $0.9 \mathrm{~m}$-thick slab. Mimouni \& Laloui (2015) indicated a thickness of the slab of $0.5 \mathrm{~m}$ based on the smallest value of height of the cross-section characterising the central zone of this element in plan view. The thickness considered in this work (which corresponds to that proposed by Di Donna et al. (2016) and is supposed to be constant over the breadth and length of the slab in the numerical model) is the dimension of the height of the cross-section of the slab at the joint zones with the piles. Because this latter value of height is considered to predominantly characterise the response of the piles over the breadth and length of the slab, it is accounted for in the following analyses. In plan view, the energy piles form a triangle within a $4.21 \mathrm{~m}$ square in which the central pile, EP1, is located $3 \mathrm{~m}$ from the others, EP2, 3 and 4 . The energy piles are $28 \mathrm{~m}$ long and $0.9 \mathrm{~m}$ in diameter, and the conventional piles are $16 \mathrm{~m}$ long and $0.6 \mathrm{~m}$ in diameter. All of the piles were bored, cast on site and are made 
of reinforced concrete. Vertical loads of 0, 800, 2200 and $2100 \mathrm{kN}$ are applied to energy piles EP1, 2, 3 and 4, respectively. Vertical loads of $300 \mathrm{kN}$ are applied to each of the conventional piles. The values of vertical loads are characteristic values that were calculated by the company involved in the geotechnical and structural designs of the foundation. Throughout the design process, these loads were considered as imposed on the uppermost surface of the slab in correspondence with the area delimited by the cross-sectional surface of the underlying piles. This loading situation is considered in this work (as in that presented by Di Donna et al. (2016)). The energy piles were equipped with four 24-m-long high-density polyethylene U-loops that are connected in series. The inlets and outlets of the absorber pipes were thermally insulated to a depth of $4 \mathrm{~m}$ below the pile heads to limit the influence of the climatic conditions on the heat exchange process.

All of the energy piles were instrumented with vibrating wire strain gauges and thermocouples along their lengths (model EM-5 from Roctest) and optical fibres (Sofo system from Roctest), as well as with pressure cells (model TPC from Roctest) at their toes. Piezometers (model PWS with stainless steel filters from Roctest) and thermistors (model TH-T from Roctest) (labelled P+T1 and P+T2 in Fig. 1(c)) were also installed in two boreholes in the soil. These instruments (see Fig. 1(c)) allow the thermo-hydro-mechanical response of the northwestern corner of the foundation to be monitored during the simulation of potentially different operations of the energy piles by way of the use of a dedicated heating module.

The soil stratigraphy of the site (see Fig. 1(d)) was extrapolated based on information that was obtained during the construction of the foundation and data from Laloui et al. (2003, 2006) for another experimental site that is located $200 \mathrm{~m}$ away at the Swiss Federal Institute of Technology in Lausanne (EPFL). During the construction of the piles, the groundwater table was located at the top of the deposit, which is estimated to be in an overconsolidated condition. Layers of alluvial soil and sandy-gravelly moraine were encountered at shallow depths. The upper soil profile of the alluvial soil was inferred to reach a depth from the uppermost surface of the successively built slab of $z=8.6 \mathrm{~m}$. The lower sandy-gravelly moraine layer was located between depths of $z=8.6$ and $16.6 \mathrm{~m}$ (Laloui et al., 2003, 2006). A thin layer of bottom moraine was present below the sandy-gravelly moraine layer between depths of $z=16 \cdot 6$ and $20 \cdot 1 \mathrm{~m}$ and laid on a molasse layer. The energy piles were socketed $8.8 \mathrm{~m}$ into this bottom molasse layer from a depth of $z=20 \cdot 1 \mathrm{~m}$ to a depth of $z=28.9 \mathrm{~m}$.

\section{Features of the experimental test}

The experimental test involved the application of a heatingpassive cooling cycle to energy pile EP1, which was the only energy pile of the group that operated as a geothermal heat exchanger (see Fig. 1(b)). A dedicated heating module (Mattsson et al., 2008) was used for applying the heatingpassive cooling cycle to EP1. The test consisted of three phases. The first phase involved the circulation of the heat carrier fluid in the pipes of energy pile EP1 for 1 day with the heater turned off to determine the average ground temperature at the site. The second phase consisted of applying a constant thermal power of $3 \mathrm{~kW}$ to energy pile EP1 for approximately 5 months (156 days). The third and final phase involved the passive cooling of the foundation by switching the heater off and allowing the heat carrier fluid in the pipes of EP1 to circulate for approximately 10 months (300 days). These features make the experiment representative of oneseason cooling and/or thermal energy storage applications for energy piles. Throughout the test, a constant flow rate of $21 \mathrm{l} / \mathrm{min}$ was applied to the circulating fluid in the pipes of the operating energy pile EP1. The inlet temperature and velocity of the fluid were continuously recorded, and the strain, temperature and stress variations of EP1 and of the nonoperating energy piles EP2, 3 and 4 were monitored over time. The variations in the pore water pressure and temperature in the two soil profiles $(\mathrm{P}+\mathrm{T} 1$ and $\mathrm{P}+\mathrm{T} 2)$ were also measured.

\section{NUMERICAL MODELLING}

This section presents $(a)$ the features of the finite-element model that was constructed to simulate the experimental test and to obtain complementary information about the problem that may have been difficult if not impossible to collect otherwise; $(b)$ the assumptions and main characteristics of the mathematical formulation that was used for the numerical analyses; and $(c)$ the boundary conditions and material properties that were used for the numerical simulations. Detailed information about the mathematical formulation that was used for the numerical analyses is presented by Batini et al. (2015).

\section{Finite-element model}

A 3D finite-element model of the site was developed using the software Comsol Multiphysics (Comsol, 2014) (see Fig. 2). The $80 \times 70 \times 60 \mathrm{~m}^{3}$ model is composed of 438443 tetrahedral, prismatic, triangular, quadrilateral, linear and vertex elements. The model reproduces the entire foundation
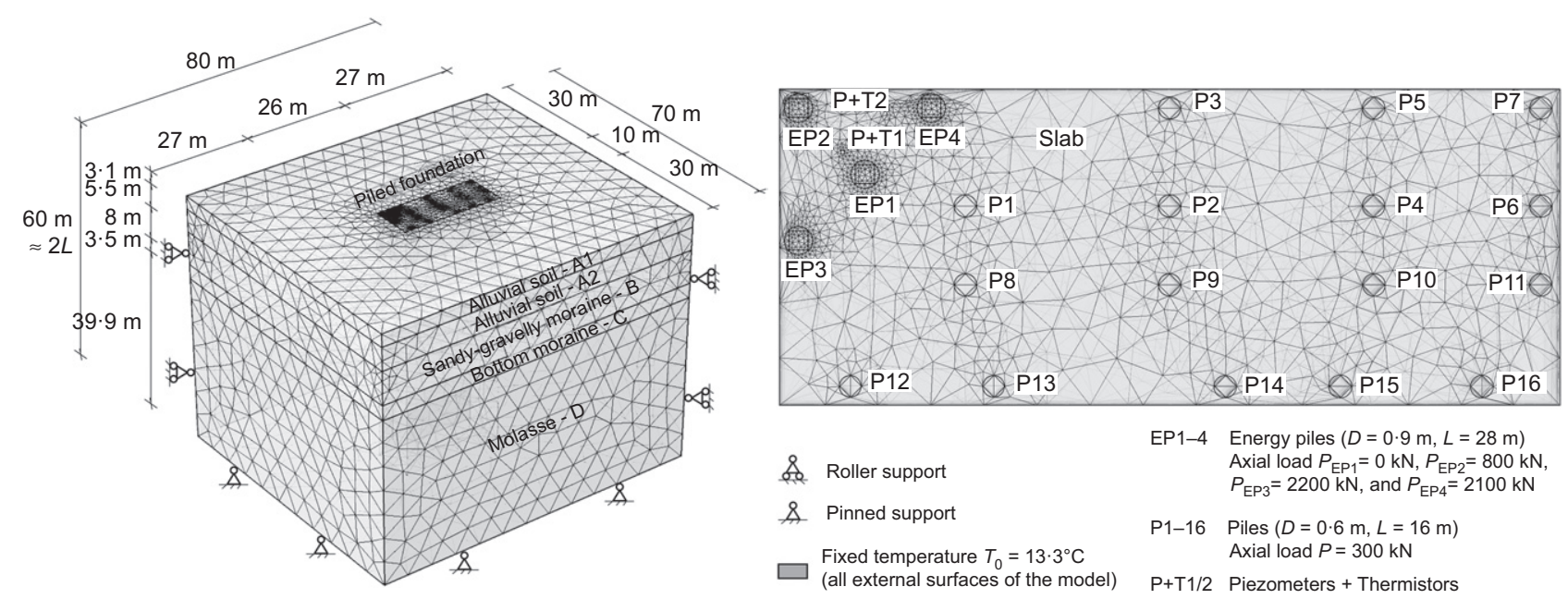

Fig. 2. Geometry and boundary conditions of the finite-element model of the foundation 
supporting the water retention tank. It also accounts for the presence of the pipes in the energy piles through linear entities in which a heat carrier fluid is assumed to flow, which allows the problem of the heat exchange that occurs in the pipes-pile-soil system to be considered.

\section{Modelling choices}

The numerical analysis of the response of the reinforced concrete foundation in the soil under mechanical and thermal loads is based on the following assumptions: $(a)$ the displacements and deformations of all of the materials can be representatively described through a linear kinematic approach under quasi-static conditions (i.e. negligible inertial effects); (b) the materials that constitute the pile foundation are considered to be isotropic with pores that are fully filled by air and are assumed to be purely conductive domains with equivalent thermo-physical properties that are given by the fluid and the solid phases; $(c)$ the materials that make up the soil layers are assumed to be isotropic, fully saturated by water and purely conductive domains with equivalent thermo-physical properties that are given by the fluid and the solid phases; $(d)$ the loads that are associated with this problem have a negligible impact on the variation of the hydraulic field in the soil; and (e) all the materials are considered to be representatively described by linear thermo-elastic behaviours.

Under these conditions, a thermo-mechanical mathematical formulation is employed.

Water may be potentially present in some of the pores characterising the buried concrete in the real case, especially in the regions of this material adjacent to the soil. This fact may lead to a greater thermal conductivity of the concrete compared to that assumed in the present numerical analyses. While this phenomenon cannot be verified with reference to the tested foundation, the adherence between the results of the numerical analyses and the experimental test presented in the later section entitled 'Comparison between experimental and numerical results' supports the hypothesis made.

\section{Boundary and initial conditions}

Restrictions are applied to both the vertical and horizontal displacements on the base of the model (i.e. pinned boundary) and to the horizontal displacements on the sides (i.e. roller boundaries). The initial stress state due to gravity in the foundation and the soil is considered to be geostatic and assumes a coefficient of earth pressure at rest of $K_{0}=1$. This value of $K_{0}$ approximately characterises the in situ stress state based on the values of the coefficients of earth pressure at rest of the different soil layers that may be calculated according to the formula proposed by Schmidt (1966) through the values of angle of shear strength proposed by Di Donna et al. (2016) and assuming a constant value of overconsolidation ratio, $\mathrm{OCR}=4$, with depth. The considered value of OCR is based on experimental evidence (Laloui et al., 1999) for the moraine layers surrounding the foundation tested by Laloui et al. (2003) that were also identified in this study. The same OCR was assumed to characterise the other soil layers surrounding the foundation tested in this study for hypothesis. No residual stresses from the installation of the piles are considered in these elements and in the adjacent region of soil. This hypothesis may not be completely representative of reality but can be applied successfully in almost all methods of pile groups deformation analysis by choosing appropriate values of the soil moduli (Poulos \& Davis, 1980). Perfect contact between the piles and the soil is considered, that is, the pile-soil interfaces are not modelled. The piles are modelled as perfectly jointed members (full moment connection) with the slab, such an element

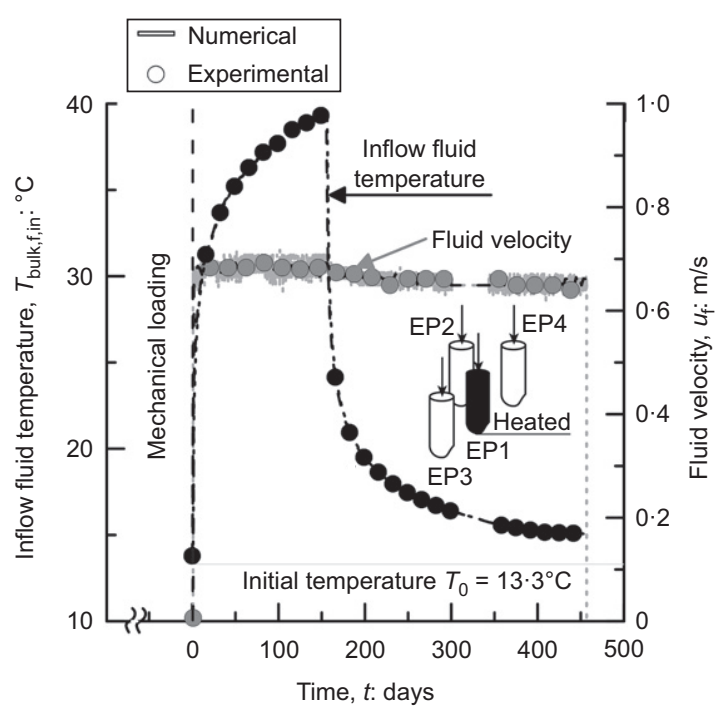

Fig. 3. Experimentally and numerically imposed inflow temperatures and velocities of fluid circulating in pipes of operating energy pile EP1 with time

being characterised by a perfect contact with the surrounding soil. The pipes in the energy piles are considered to have a perfect contact with the surrounding reinforced concrete. The temperature is fixed on all six external boundaries of the model $\left(T=13 \cdot 3^{\circ} \mathrm{C}\right)$. The initial temperatures in the pipes, energy and conventional piles, slab and soil are set to $T_{0}=13 \cdot 3^{\circ} \mathrm{C}$, which is the average temperature that was recorded at the beginning of the experimental test between depths of $z=4.9$ and $28.9 \mathrm{~m}$ from the surface of the site. This temperature corresponds to the portions of the energy piles that are not thermally insulated. The fluid that circulates inside the pipes is water. The inner diameter of the pipes is $\phi=26.2 \mathrm{~mm}$ (the outer diameter is $32 \mathrm{~mm}$ and the wall thickness is $2.9 \mathrm{~mm})$. A thermal conductivity of $\lambda_{\mathrm{p}}=0 \mathrm{~W} /\left(\mathrm{m}{ }^{\circ} \mathrm{C}\right)$ is imposed in the shallowest four meters of the inlet and outlet of the pipes to simulate the thermal insulation near the ground surface. The trends of the inlet temperature and velocity of the fluid in the pipes that were experimentally recorded throughout the test are considered as input parameters for the numerical simulations (see Fig. 3).

\section{Classification of the numerical simulations and material properties}

Two kinds of numerical simulations were performed in this study: Class B1 and Class C1 predictions (Lambe, 1973).

A Class B1 prediction was carried out while the modelled in situ test was performed and with the associated results available. This prediction employed the material properties proposed by Di Donna et al. (2016) for the characterisation of the site.

Different Class $\mathrm{Cl}$ predictions were carried out after the modelled in situ test was performed and with the associated results available. The final Class $\mathrm{C} 1$ prediction employed the material properties proposed by Di Donna et al. (2016) with two main changes. These changes included the linear thermal expansion coefficient of the soil layers B, C and D, as well as the thermal conductivity of the solid particles of all of the soil layers. The variation of the former parameter was based on the ranges of variability that typically characterise the thermal expansion coefficient of moraine and molasse deposits in the geographical area of Lausanne. The variation was necessary to reproduce the thermally induced mechanical behaviour of the foundation at successive stages of the 
Table 1. Material properties used for the Class $\mathrm{C} 1$ and $\mathrm{B} 1$ (in brackets) numerical predictions

\begin{tabular}{|c|c|c|c|c|c|c|c|}
\hline \multicolumn{8}{|c|}{ Soil layers } \\
\hline & $\begin{array}{l}\text { Young's } \\
\text { modulus, } \\
E: \mathrm{MPa}\end{array}$ & $\begin{array}{l}\text { Poisson } \\
\text { ratio, } v\end{array}$ & $\begin{array}{c}\text { Porosity, } \\
n\end{array}$ & $\begin{array}{c}\text { Density of } \\
\text { solid particles, } \\
\rho_{\mathrm{s}}: \mathrm{kg} / \mathrm{m}^{3}\end{array}$ & $\begin{array}{c}\text { Specific heat of } \\
\text { solid particles, } \\
c_{\mathrm{p}, \mathrm{s}}: \mathrm{J} /\left(\mathrm{kg}{ }^{\circ} \mathrm{C}\right)\end{array}$ & $\begin{array}{c}\text { Thermal conductivity } \\
\text { of solid particles, } \\
\lambda_{\mathrm{s}}: \mathrm{W} /\left(\mathrm{m}^{\circ} \mathrm{C}\right)\end{array}$ & $\begin{array}{l}\text { Linear thermal } \\
\text { expansion } \\
\text { coefficient, } \alpha: 1 /{ }^{\circ} \mathrm{C}\end{array}$ \\
\hline $\begin{array}{l}\text { A } \\
\text { B } \\
\text { C } \\
\text { D }\end{array}$ & $\begin{array}{r}190 \\
84 \\
90 \\
3000\end{array}$ & $\begin{array}{l}0 \cdot 22 \\
0 \cdot 4 \\
0 \cdot 4 \\
0 \cdot 3\end{array}$ & $\begin{array}{l}0 \cdot 1 \\
0 \cdot 35 \\
0 \cdot 3 \\
0 \cdot 1\end{array}$ & $\begin{array}{l}2769 \\
2735 \\
2740 \\
2167\end{array}$ & $\begin{array}{l}880 \\
890 \\
890 \\
923\end{array}$ & $\begin{array}{l}1 \cdot 49(3 \cdot 38) \\
3 \cdot 68(4 \cdot 45) \\
3 \cdot 46(4 \cdot 17) \\
3 \cdot 82(3 \cdot 38)\end{array}$ & $\begin{array}{l}3 \cdot 3 \times 10^{-6} \\
3 \cdot 3 \times 10^{-6}\left(3 \cdot 3 \times 10^{-5}\right) \\
3 \cdot 3 \times 10^{-6}\left(3 \cdot 3 \times 10^{-5}\right) \\
2 \cdot 3 \times 10^{-5}\left(3 \cdot 3 \times 10^{-7}\right)\end{array}$ \\
\hline \multicolumn{8}{|c|}{ Reinforced concrete piles and slab } \\
\hline $\begin{array}{l}\text { Piles } \\
\text { Slab }\end{array}$ & $\begin{array}{l}28000 \\
35000\end{array}$ & $\begin{array}{l}0 \cdot 25 \\
0 \cdot 25\end{array}$ & $\begin{array}{l}0 \cdot 1 \\
0 \cdot 1\end{array}$ & $\begin{array}{l}2722 \\
2722\end{array}$ & $\begin{array}{l}837 \\
837\end{array}$ & $\begin{array}{l}1.628 \\
1.628\end{array}$ & $\begin{array}{l}1 \times 10^{-5} \\
1 \times 10^{-5}\end{array}$ \\
\hline \multicolumn{8}{|c|}{ High-density polyethylene pipes } \\
\hline Pipes & - & - & - & - & - & $\begin{array}{c}\text { Thermal conductivity of } \\
\text { the pipe, } \lambda_{\mathrm{p}}: \mathrm{W} /\left(\mathrm{m}{ }^{\circ} \mathrm{C}\right) \\
0.42\end{array}$ & - \\
\hline
\end{tabular}

heating phase of EP1. Furthermore, the variation suggests an inhomogeneity of such material property for the considered layers based on the difference with the values presented by Laloui et al. (2006) for another experimental site at the EPFL campus that were considered by Di Donna et al. (2016). The variation of the latter parameter was based on the determination (without accounting for capacitive effects) of an effective thermal conductivity for the soil deposit of $\lambda_{\text {eff }}=2.78 \mathrm{~W} /\left(\mathrm{m}^{\circ} \mathrm{C}\right)$. This average value of effective thermal conductivity was determined experimentally with reference to the soil around the thermally active portion of the operating energy pile EP1 and is slightly lower than the value of $\lambda_{\text {eff }}=3 \cdot 1 \mathrm{~W} /\left(\mathrm{m}{ }^{\circ} \mathrm{C}\right)$ suggested by Mimouni \& Laloui (2015) that was considered by Di Donna et al. (2016). Knowledge of $\lambda_{\text {eff }}$, together with the porosity values of all of the soil layers, allowed calculation of the thermal conductivity of solid particles of the various layers that were subsequently modified based on a comparison with the experimental results for best capturing the thermal behaviour of the foundation.

Table 1 summarises the material properties considered for the numerical simulations (the values of the material properties presented in brackets are those that were initially used for the Class B1 prediction).

\section{COMPARISON BETWEEN EXPERIMENTAL AND NUMERICAL RESULTS}

This section compares the experimental data that were collected during the development of the full-scale in situ test and the numerical results that were obtained through the final Class $\mathrm{C} 1$ prediction. A discussion of the results obtained throughout the numerical prediction process (Class $\mathrm{B} 1$ and $\mathrm{C} 1$ predictions) is presented in the later section entitled 'Discussion'.

The experimental and numerical data include variations of the parameters from the beginning of the test over time. Therefore, they reflect the impact of the geothermal operation of energy pile EP1 on the thermo-mechanical behaviour of the foundation. The stress states that are generated from body loads in the different media (i.e. in-situ conditions) and from the application of the mechanical loads of the superstructure to the piles are not included in the stress and strain curves.

Compressive stresses, contractive strains and downward displacements (i.e. settlements) are considered to be positive.

A problem arose when comparing the readings of the strain gauges and thermocouples that were installed along the piles with the numerical results because even though these instruments were fixed along the reinforcing cages, their precise positions were not known. The approach that was used to overcome this issue was to find the location in the numerical model along a $0 \cdot 76-\mathrm{m}$-dia. circle (corresponding to the diameter of the reinforcing cages placed in the energy piles in the reality) that was centred on the pile axes where the temperature profiles matched best, and then compare the strain profiles at the same location. A similar problem occurred when comparing the readings of the pressure cells because the recorded data referred to an area of a $0 \cdot 23$-m-dia. circle that was centred at the pile toes (corresponding to the region occupied by the pressure cells placed in the energy piles in reality), whereas the numerical results referred to point graphs. In this case, the location in the region of interest where the temperature data matched best was identified, and the stress data were then compared. The choice of these 'temperature-driven' approaches was based on the important role that changes of temperature play in the variation of the mechanical behaviour of energy piles. Such an approach was also needed due to the inhomogeneity of the temperature, strain, stress and displacement fields that were observed within the cross-sections of the piles with depth. Average variations of these fields up to $20 \%$ were observed in this study along the tested piles over their cross-sectional area. The inhomogeneity of these fields has also been recently highlighted by Caulk et al. (2016) and Abdelaziz \& Ozudogru (2016).

\section{Temperature variations along the energy piles}

Figure 4 presents the temperature variations that were determined experimentally through the readings of the thermocouples and numerically through the finite-element model along the lengths of the operating energy pile EP1 and of the non-operating energy piles EP2, 3 and 4.

The geothermal operation of energy pile EP1 involved average temperature changes along its uninsulated portion of $\Delta T=5,10,15$ and $20^{\circ} \mathrm{C}$ after $t=2,8,35$ and 156 days, respectively. These changes were observed in both the experimental and numerical results (see Fig. 4(a)).

After $t=2$ and 8 days (i.e. during the early stages of the heating phase of energy pile EP1), the corresponding portions of the non-operating energy piles EP2, 3 and 4 were characterised by no changes in temperature. However, temperature changes were observed over time because heat diffused through the soil from EP1 and indirectly heated them. After $t=35$ and 156 days (i.e. during the successive 


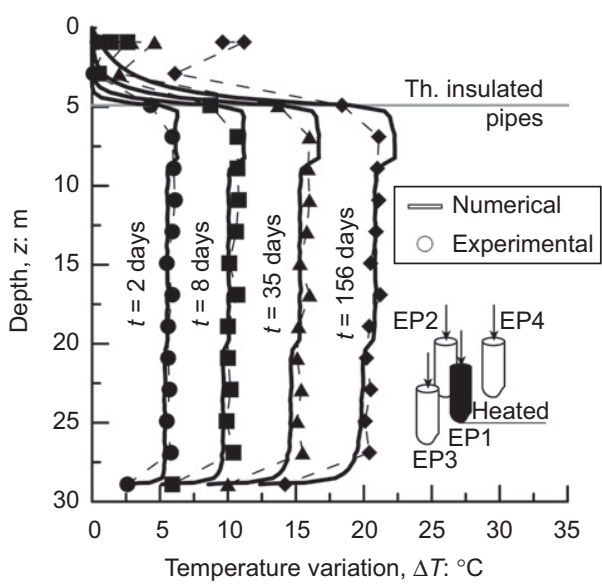

(a)

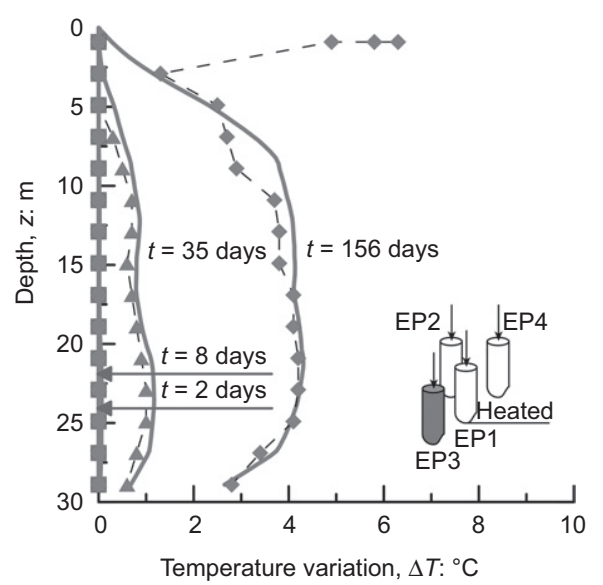

(c)

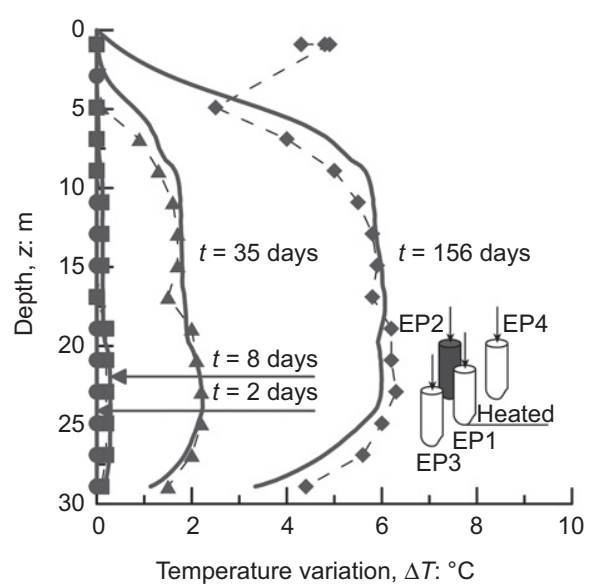

(b)

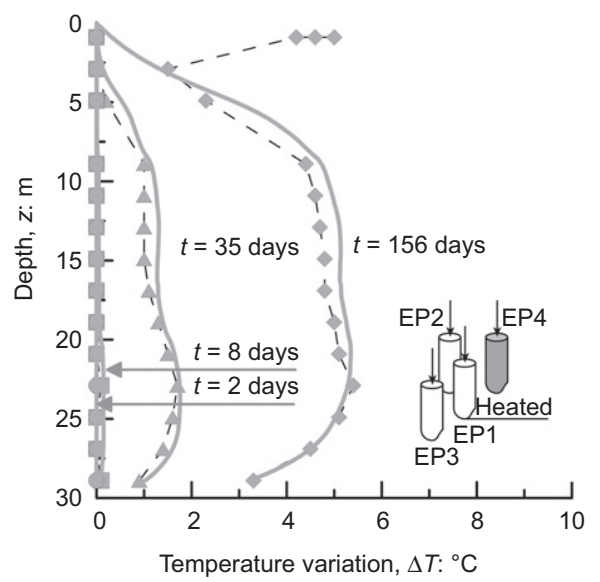

(d)

Fig. 4. Comparison between experimental and numerical temperature variations observed along (a) the operating energy pile EP1 and (b), (c), (d) the non-operating energy piles EP2, 3 and 4, after $t=2,8,35$ and 156 days of testing

stages of the heating phase of EP1), heat diffusion resulted in average experimental temperature variations of $\Delta T=1 \cdot 6,0 \cdot 7$ and $1 \cdot 1{ }^{\circ} \mathrm{C}$ and $\Delta T=5 \cdot 3,3.6$ and $4.5^{\circ} \mathrm{C}$, respectively. The numerical results showed slightly higher average temperature changes than the experimental results (see Figs 4(b)-4(d)). This discrepancy was attributed to differences between the actual and modelled heat diffusion processes in the foundation, which were inferred to be caused by $(a)$ potential inhomogeneity (spatial and of material properties) of the soil layers of the site that were not accounted for in the numerical model and $(b)$ different positions of the pipes inside EP1 than those that were considered in the simulation.

In addition to the observed temperature changes with time that corresponded to the uninsulated portion of energy pile EP1, temperature variations also occurred in the shallowest $4 \mathrm{~m}$ of EP1, 2, 3 and 4 even though the pipes of EP1 were thermally insulated at these depths. This behaviour was observed in both the experimental and numerical results and was attributed to the impact of the heat exchange operation of energy pile EP1 on the thermal field characterising the shallower portion of the foundation. The experimental results indicated changes in temperature at the surface of the foundation, which were attributed to the variation of the surface thermal conditions during the experimental test. The numerical results showed slightly smaller temperature variations in the shallowest $4 \mathrm{~m}$ of all of the piles than the experimental results. They also indicated that no changes in temperature occurred at the surface of the foundation. These results were consistent with the fixed temperature boundary condition that was imposed on the top surface of the numerical model. As will be illustrated by the results presented below, although not thoroughly representative of the real case, this boundary condition did not compromise the accuracy of the numerical analysis in representing the thermally induced mechanical behaviour of the foundation. Furthermore, this boundary condition did allow the overall thermal behaviour of the foundation to be captured in view of the close comparison between the trends of the outflow fluid temperature from the pipes of EP1 determined experimentally through the readings of the heating module and numerically through the finite-element model (see Fig. 5).

\section{Temperature trends at the energy pile toes}

Figure 6 presents the temperature variations that were determined experimentally through the readings of the pressure cells and numerically through the finite-element model at the energy pile toes.

The results show progressive changes in temperature at the toes of energy piles EP1, 2, 3 and 4. The geothermal operation of energy pile EP1 induced a progressive increase in temperature at its toe up to the experimentally observed value of $\Delta T=13 \cdot 4^{\circ} \mathrm{C}$ after $t=156$ days. Temperature changes were not observed in the non-operating energy piles EP2, 3 and 4 within $t=10$ days of testing. However, after approximately $t=10$ days, the temperatures at these elements increased with time due to the diffusion of heat through the soil from EP1. An average temperature change of $\Delta T=3 \cdot 5^{\circ} \mathrm{C}$ was observed in the experiment at the toe of these elements after $t=156$ days. The temperature rises numerically determined at the toes of EP2, 3 and 4 at the early and successive stages of the heating phase of EP1 were slightly faster and 
slower than those observed experimentally, respectively. A residual temperature change was numerically determined at the toe of the operating energy pile EP1 toward the end of the test differently to the negligible temperature change that was observed experimentally. Both the experimental and

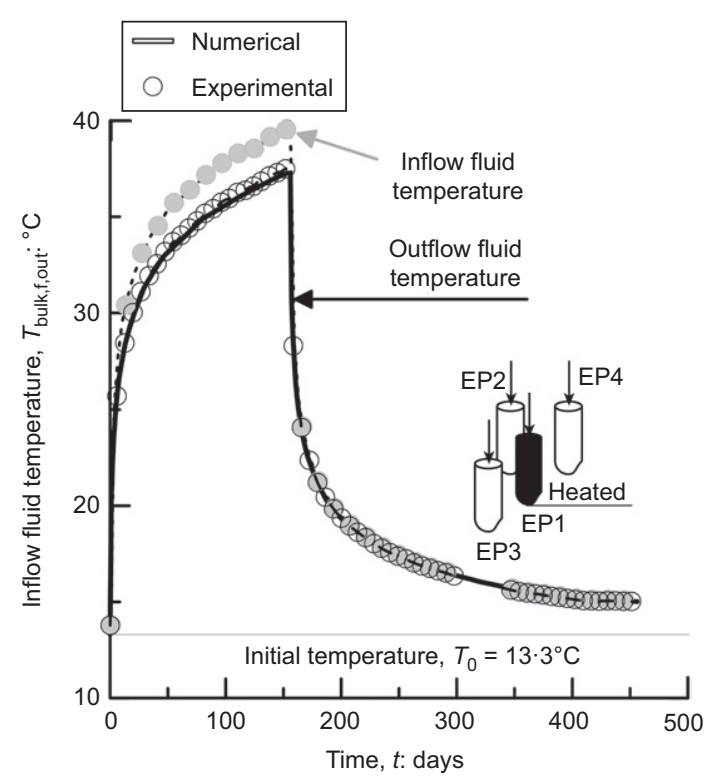

Fig. 5. Comparison between experimental and numerical trends of fluid temperature flowing from pipes of operating energy pile EP1 numerical results agreed well in indicating a residual average temperature change at the toes of the non-operating energy piles EP2, 3 and 4 toward the end of the test. The differences between the numerical and experimental results were attributed to: $(a)$ differences between the materials description and the geometry of the pipes in EP1 in the numerical model and those characterising the real case; and $(b)$ different sensitivities to a temperature variation of the nodes of the finiteelement model (that were used to determine the temperature variations at the pile toes) and of the pressure cells. The impact of all of these aspects was more notable at the late stages of the test (e.g. passive cooling phase of EP1) because capacity effects governed the heat exchange process characterising the foundation. The considered differences may be associated with localised variations between the modelled and actual mechanical behaviours of the foundation addressed in the following.

\section{Temperature variations in the soil}

Figure 7 shows the temperature variations in the soil that were determined experimentally through the readings of the thermistors and numerically through the finiteelement model. The changes in temperature along the lengths of profiles $\mathrm{P}+\mathrm{T} 1$ (see Fig. 7(a)) and $\mathrm{P}+\mathrm{T} 2$ (see Fig. 7(b)) show the stages of the test during which the operating energy pile EP1 was subjected to average temperature changes of $\Delta T=5,10,15$ and $20^{\circ} \mathrm{C}$ (i.e. at $t=2$, 8,35 and 156 days of testing, respectively). The trends of temperature variations (see Fig. 7(c)) refer to selected points along the profiles.

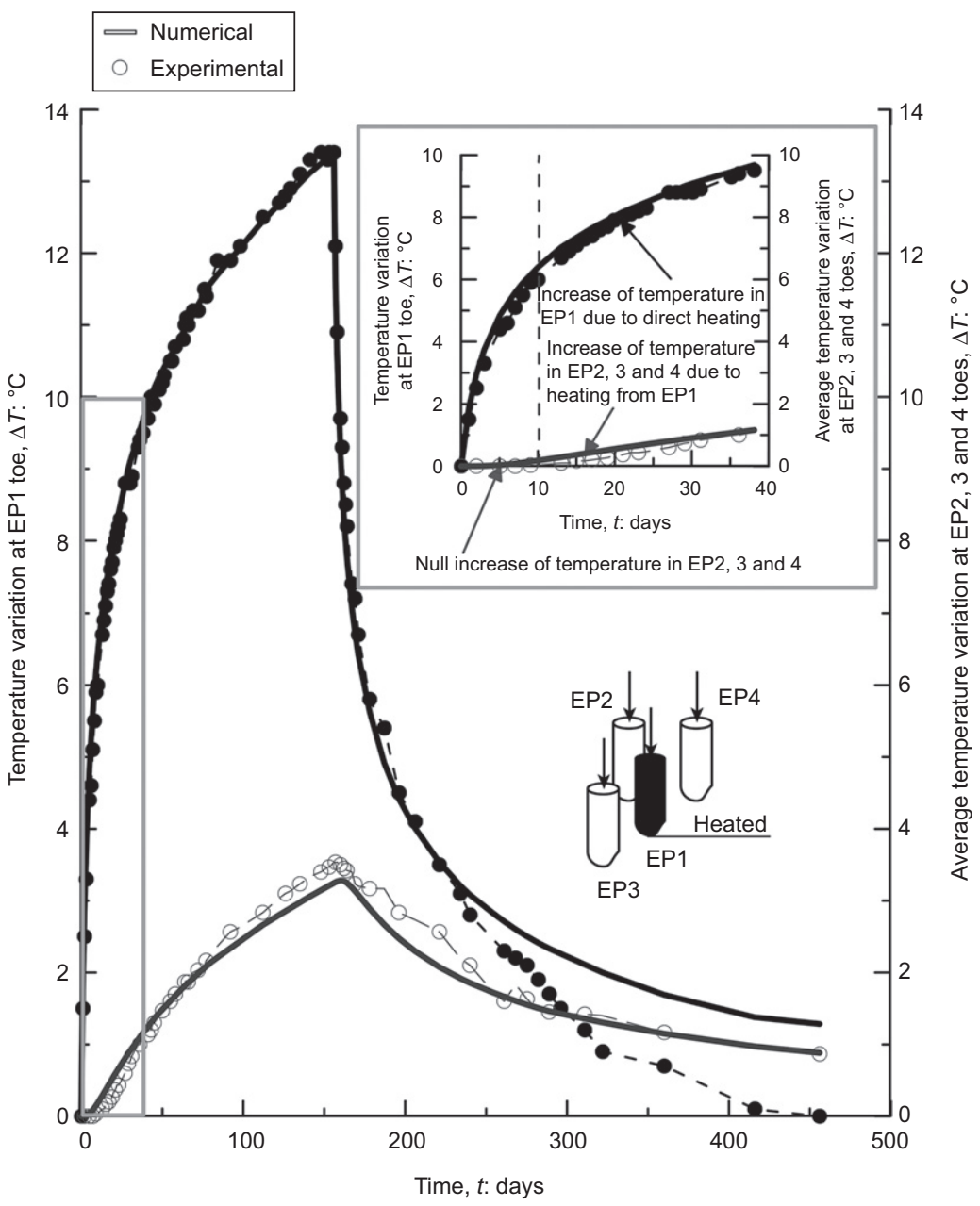

Fig. 6. Comparison between experimental and numerical temperature variations observed at energy pile toes with time 


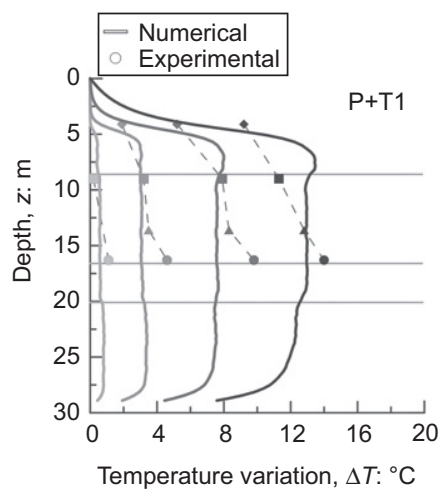

(a)

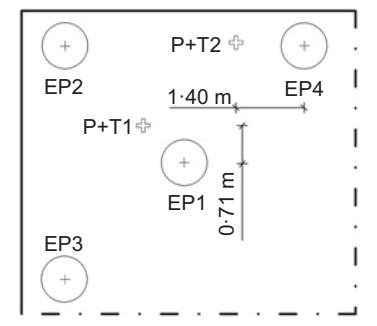

Plan view of the foundation corner (view out of scale)

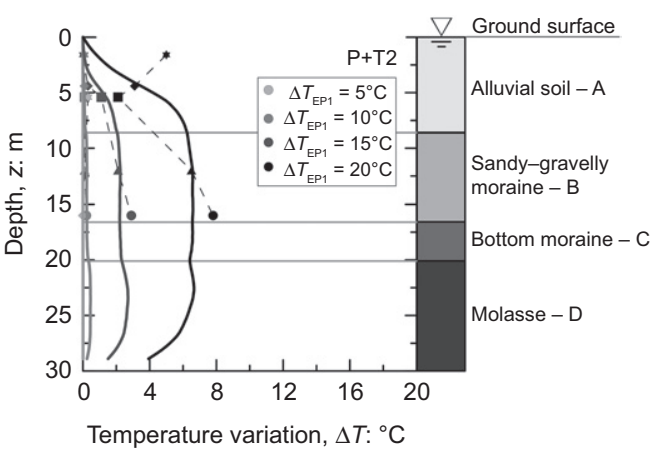

(b)

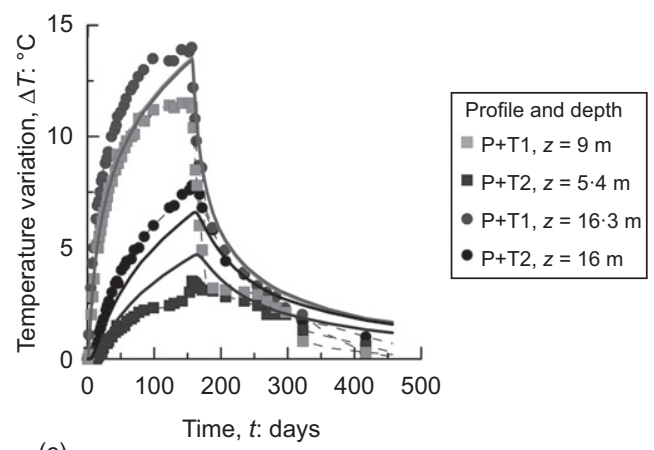

(c)

Fig. 7. Comparison between the experimental and numerical temperature variations along profiles (a) $P+T 1$ and $(b) P+T 2$ in the soil at the time steps at which the operating energy pile EP1 was subjected to average temperature changes of $\Delta T=5,10,15$ and $20^{\circ} \mathrm{C}(t=2,8,35$ and 156 days of testing, respectively). (c) Trends of temperature variations at selected points along the profiles

The heating of energy pile EP1 had a notable impact on the temperature field of the surrounding soil. The experimental results show that after $t=156$ days, the profile at a radial distance of $1 \mathrm{~m}$ from the axis of the EP1 (i.e. $\mathrm{P}+\mathrm{T} 1$ ) was subjected to an average temperature change of $\Delta T=12^{\circ} \mathrm{C}$ (see Fig. 7(a)). At the same time, a lower average temperature change of $\Delta T=5^{\circ} \mathrm{C}$ was observed along the profile at a radial distance of $2.2 \mathrm{~m}$ (i.e. P + T2; see Fig. 7(b)). Comparable temperature changes were observed along the lengths of the profiles with time in the numerical results (see Fig. 7(c)), although larger changes than those that were measured experimentally were generally observed in the top portion of the foundation. This difference was again attributed to differences between the modelled and actual heat exchange processes characterising this portion of the foundation.

Inhomogeneity of the sandy-gravelly moraine was suggested by the different changes in temperature that were observed at the top and bottom of this layer (trends for points at $z=9 \mathrm{~m}$ and $z=16.3 \mathrm{~m}$ in $\mathrm{P}+\mathrm{T} 1$; see Fig. 7(c)). Because the finite-element model did not account for material inhomogeneity, this aspect of the problem was not represented by the numerical analysis. The residual temperature change previously remarked for the toes of the non-operating energy piles EP2, 3 and 4 toward the end of the test was similarly observed along the length of $\mathrm{P}+\mathrm{T} 1$ and $\mathrm{P}+\mathrm{T} 2$ during the same period of the test in both the experimental and numerical results. All of these temperature changes reflected the impact of the residual temperature variation that characterised the heat carrier fluid circulating inside the pipes of EP1 with reference to the initial condition (see Fig. 5) on the thermal field of the foundation. These temperature changes caused, in most zones of the energy pile group, residual strain and stress variations which are addressed experimentally and numerically in the following.
The comparisons between the temperature variations observed experimentally and numerically along the lengths of soil profiles $\mathrm{P}+\mathrm{T} 1$ and $\mathrm{P}+\mathrm{T} 2$ indicated greater differences than those observed along the non-operating energy piles EP2, 3 and 4. This is a consequence of the temperaturedriven approach that was used to select the potential positions of the thermocouples installed along the piles for comparing the experimental and numerical results. Different actual positions of the thermocouples in the piles, which may more closely reflect the greater differences in the temperature variations characterising the soil in correspondence with the known locations of the thermistors, cannot be discounted.

\section{Vertical strain variations along the energy piles}

Figure 8 shows the variations in vertical strain that were determined experimentally through the readings of the thermocouples and the vibrating wire strain gauges along energy piles EP1, 2, 3 and 4, and numerically through the finite-element model.

The heating due to the geothermal operation of energy pile EP1 during the first phase of the test resulted in an expansion of the portion of EP1 in which the pipes were not thermally insulated and a contraction of the thermally insulated portion because of the entrapment with the slab (see Fig. 8(a)). The contraction of the shallower portion of EP1 would not have occurred if the pipes were not thermally insulated in that region and the thermal field was more uniform along the pile length. Maximum negative (expansive) vertical strains of $\Delta \varepsilon_{z}=-22,-56,-109$ and $-167 \mu \varepsilon$ were recorded along the uninsulated portion of energy pile EP1 during the experiment when it was subjected to temperature changes of $\Delta T=5,10,15$ and $20^{\circ} \mathrm{C}$, respectively (i.e. after $t=2,8,35$ and 156 days, respectively). Maximum positive (contractive) vertical strains variations of $\Delta \varepsilon_{z}=31$, 56, 68 and $79 \mu \varepsilon$ were recorded along the insulated portion 

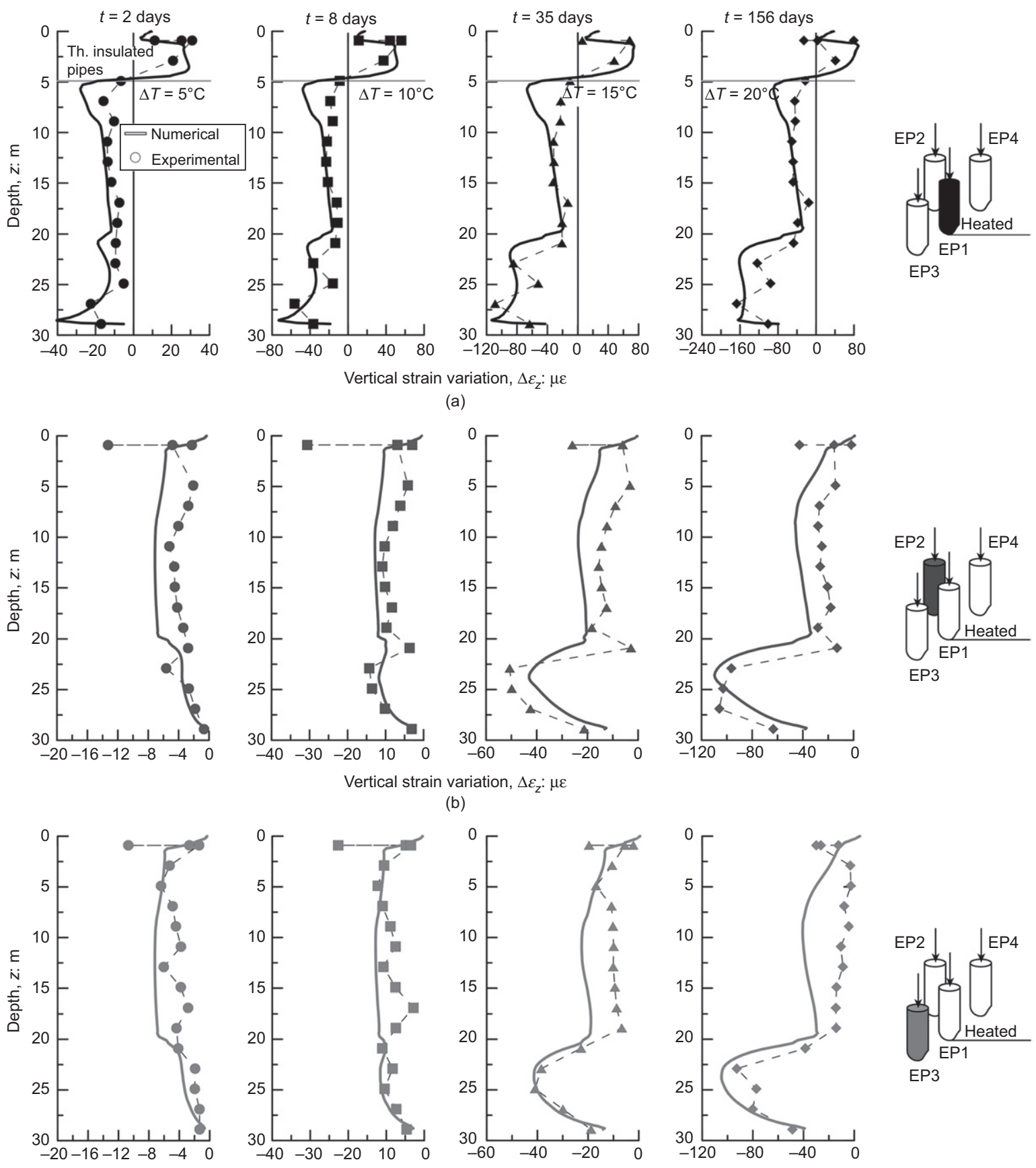

(b)
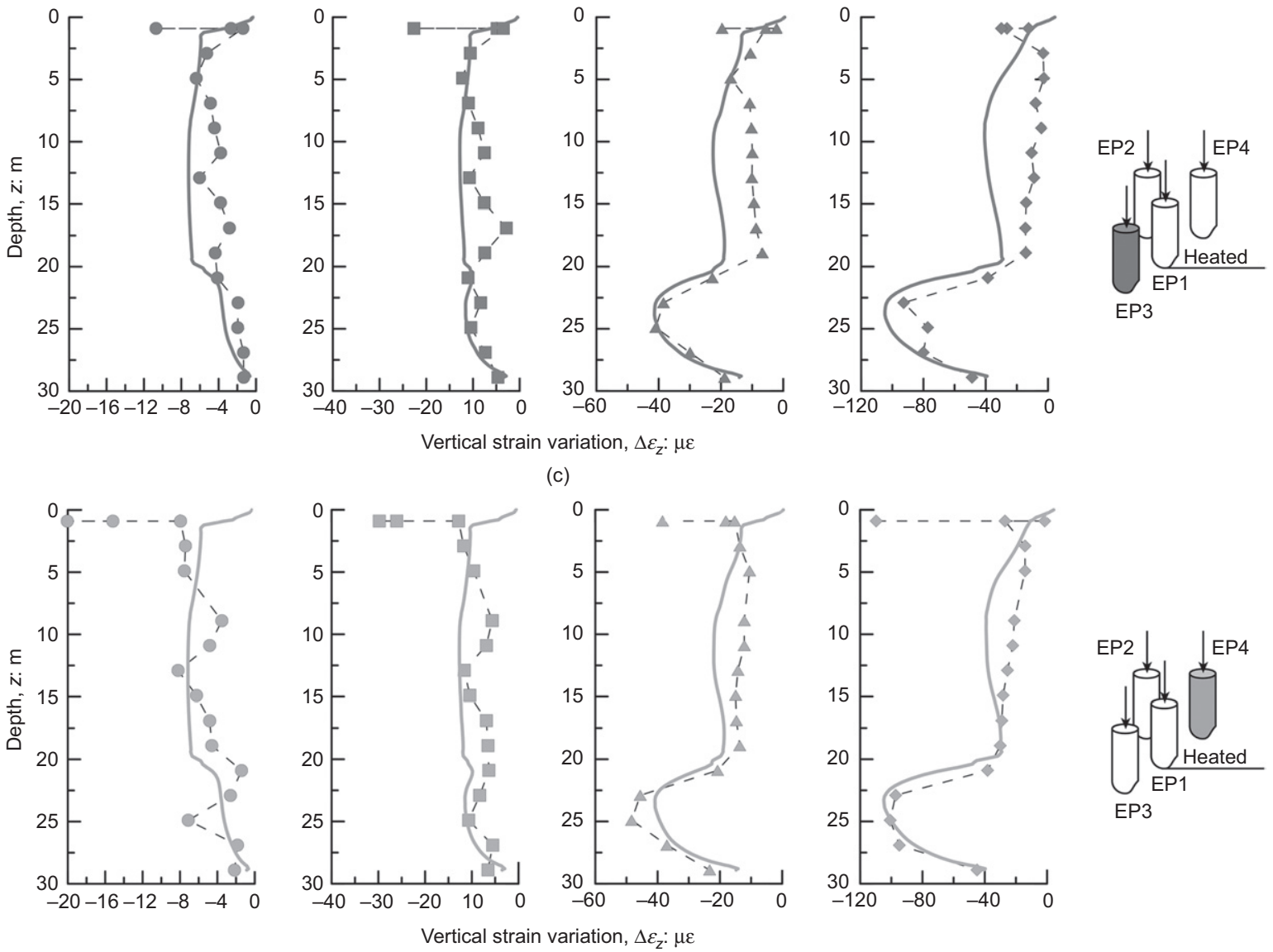

(d)

Fig. 8. Comparison between the experimental and numerical variations in vertical strain observed along (a) the operating energy pile EP1 and (b), (c), (d) the non-operating energy piles EP2, 3 and 4, after $t=2,8,35$ and 156 days of testing 
during the same stages of the test. Marked negative vertical strains were observed with time in the bottom portion of this pile. Similar results were obtained by the numerical analysis.

The heating of the operating energy pile EP1 also induced an expansion of the surrounding non-operating energy piles EP2, 3 and 4 (see Figs 8(b)-8(d)). After $t=2$ and 8 days (i.e. during the early stages of the heating phase of EP1), the expansions of EP2, 3 and 4 were caused by $(a)$ the negative strain of pile EP1 as a result of its direct heating and (b) the associated upward deformation of the slab. This deformation was thus purely mechanical (as described above, the temperature changes were zero or very small along the non-operating energy piles EP2, 3 and 4 during these stages of the test). The evolution of deformation along the piles (decreasing from top to bottom) indicates that the deformation was comparable to that caused by an upward force applied at their heads. After $t=35$ and 156 days (i.e. during the successive stages of the heating phase of EP1), the expansions of piles EP2, 3 and 4 were caused by: $(a)$ the negative strain of EP1 as a result of its direct heating; $(b)$ the associated upward deformation of the slab; $(c)$ the negative strains of these elements as a result of their indirect heating; and (d) the negative strain in the soil as a result of its heating. In contrast to the deformation of the non-operating energy piles EP2, 3 and 4 during the early stages of the geothermal operation of energy pile EP1, this deformation was characterised by both mechanical and thermal contributions. Marked negative vertical strains of up to $\Delta \varepsilon_{z}=-106 \mu \varepsilon$ were observed during these stages in the lower portions of EP2, 3 and 4 in both the experimental and numerical results. These negative strains were significantly greater than those that developed in the top portions of these elements (i.e. between $\Delta \varepsilon_{z}=-10$ and $-30 \mu \varepsilon$ ). They were also greater than the strain under free thermal expansion conditions (see Fig. 9 for energy pile EP2 after $t=156$ days), which can be calculated according to a one-dimensional scheme as

$$
\Delta \varepsilon_{\mathrm{th}, \mathrm{free}}=-\alpha_{\mathrm{EP}} \Delta T
$$

where $\alpha_{\mathrm{EP}}$ is the linear thermal expansion coefficient of the energy pile and $\Delta T$ is the observed temperature variation.

The marked expansive vertical strains that were observed in the bottom portions of all of the piles during the successive stages of the heating phase of EP1 occurred because, as heat

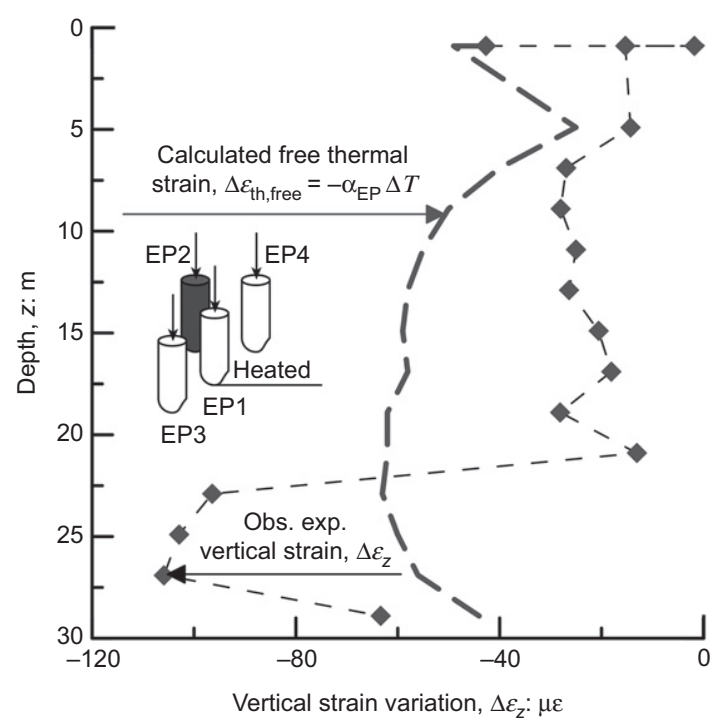

Fig. 9. Comparison between experimentally observed variations in vertical strain in the non-operating energy pile EP2 after $t=156$ days of testing and calculated with reference to free thermal expansion conditions diffused through the system, the mechanical response of the foundation was governed by the thermally induced deformation of the molasse layer. These strain variations were caused not only by the interplay between the thermally induced deformations (direct and indirect) of the piles and the slab but also and primarily by the thermally induced deformation of the soil mass (e.g. molasse layer) surrounding the piles. The value of the thermal expansion coefficient of the molasse layer, which was found to be greater than that of the piles based on the results of the numerical analysis, was the key factor of this phenomenon. Heating the very stiff molasse layer over time caused a marked expansion of this layer. This field was superimposed on the expansion field of the bottom portions of the piles. Remarkably high expansive vertical strains therefore developed in these settings.

\section{Vertical stress variations along the energy piles}

Figure 10 shows the experimental and numerical variations in vertical stress along energy piles EP1, 2, 3 and 4. The experimental vertical stress variations were calculated based on the experimentally observed vertical strain variations (using a one-dimensional scheme) as

$$
\Delta \sigma_{z}=E_{\mathrm{EP}}\left(\Delta \varepsilon_{z}-\Delta \varepsilon_{\text {th,free }}\right)
$$

where $E_{\mathrm{EP}}$ is Young's modulus of the energy pile. It is worth mentioning that the strains that are associated with free thermal expansion conditions were null for the non-operating energy piles EP2, 3 and 4 during the early stages of the geothermal operation of energy pile EP1, because no changes in temperature were observed in these elements. The numerical vertical stress variations were determined through the finite-element model.

The heating that was associated with the geothermal operation of EP1 during the first phase of the test resulted in an increasing positive (compressive) vertical stress along its length (see Fig. 10(a)). The maximum positive vertical stress change of $\Delta \sigma_{z}=5500 \mathrm{kPa}$ was observed after $t=156$ days. This phenomenon occurred because the expansive strain potential that is associated with the temperature change in the pile was restrained by the presence of the soil and slab, and caused an increase of the compressive stress in this element. The order of magnitude of the observed vertical stress variation was comparable to other experimental data from the literature (e.g. Murphy et al., 2015) that involved significant energy exploitations through the use of energy piles. Lower positive vertical stress changes were observed in the bottom portion of EP1. Consistent results were obtained by the numerical analysis.

The heating of the operating energy pile EP1 also induced vertical stress changes in the surrounding non-operating energy piles EP2, 3 and 4 (see Figs 10(b)-10(d)). After $t=2$ and 8 days (i.e. during the early stages of the heating phase of EP1), energy piles EP2, 3 and 4 were subjected to negative stress variations of up to the maximum experimental negative value of approximately $\Delta \sigma_{z}=-250 \mathrm{kPa}$ at their heads. Decreases in the negative stress variations from the top to the bottom of these elements were observed during this stage of the test in both the experimental and numerical results. These vertical stress variations were associated with the corresponding deformation field that was described previously. After $t=35$ and 156 days (i.e. during the successive stages of the heating phase of energy pile EP1), maximum positive vertical stress changes of up to $\Delta \sigma_{z}=1370 \mathrm{kPa}$ and negative vertical stress changes of up to $\Delta \sigma_{z}=-1419 \mathrm{kPa}$ were measured in EP2, 3 and 4. The previously observed negative vertical stress variations along the lengths of these elements decreased to positive values in their top portions but increased toward 

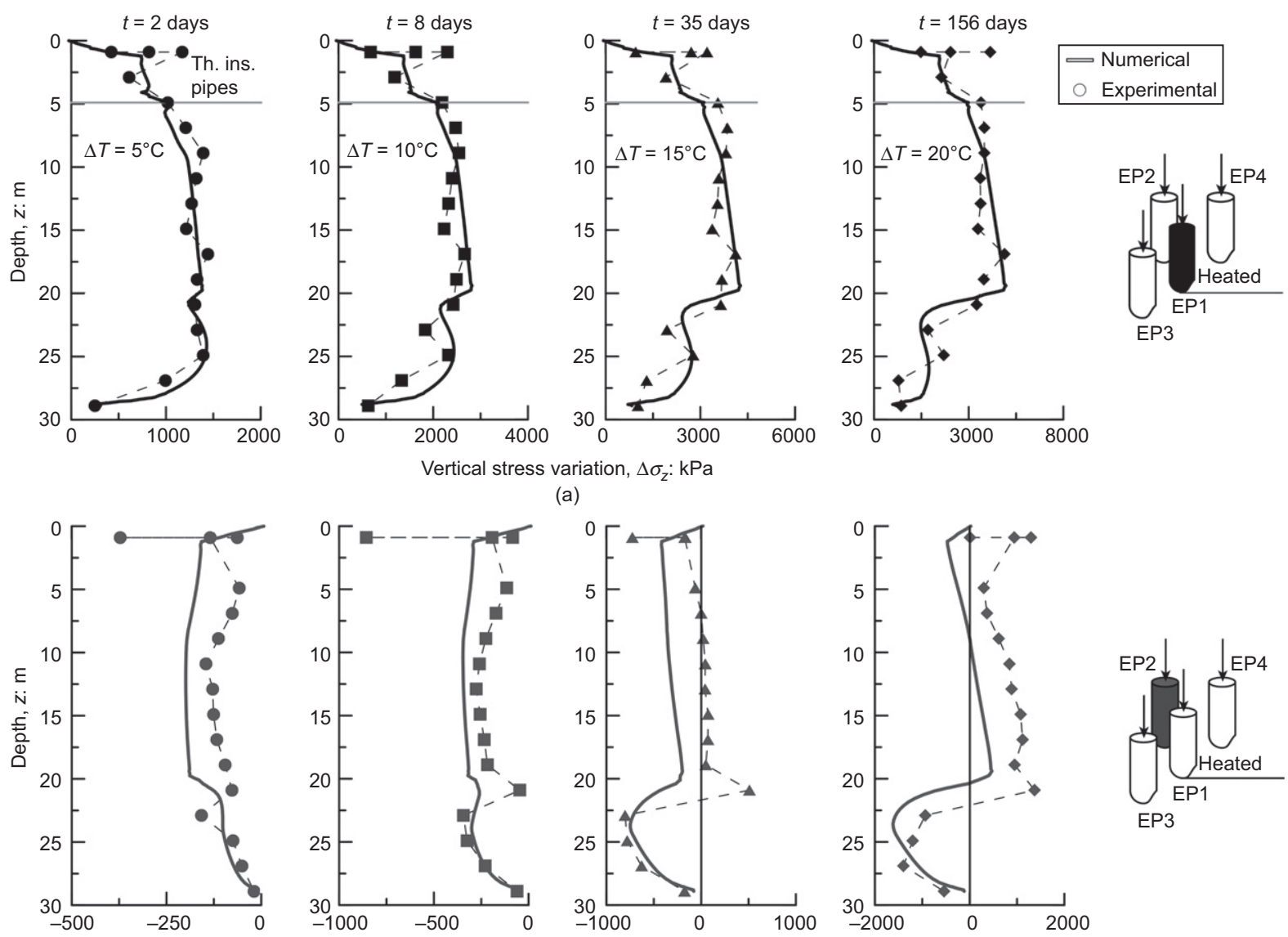

(a)
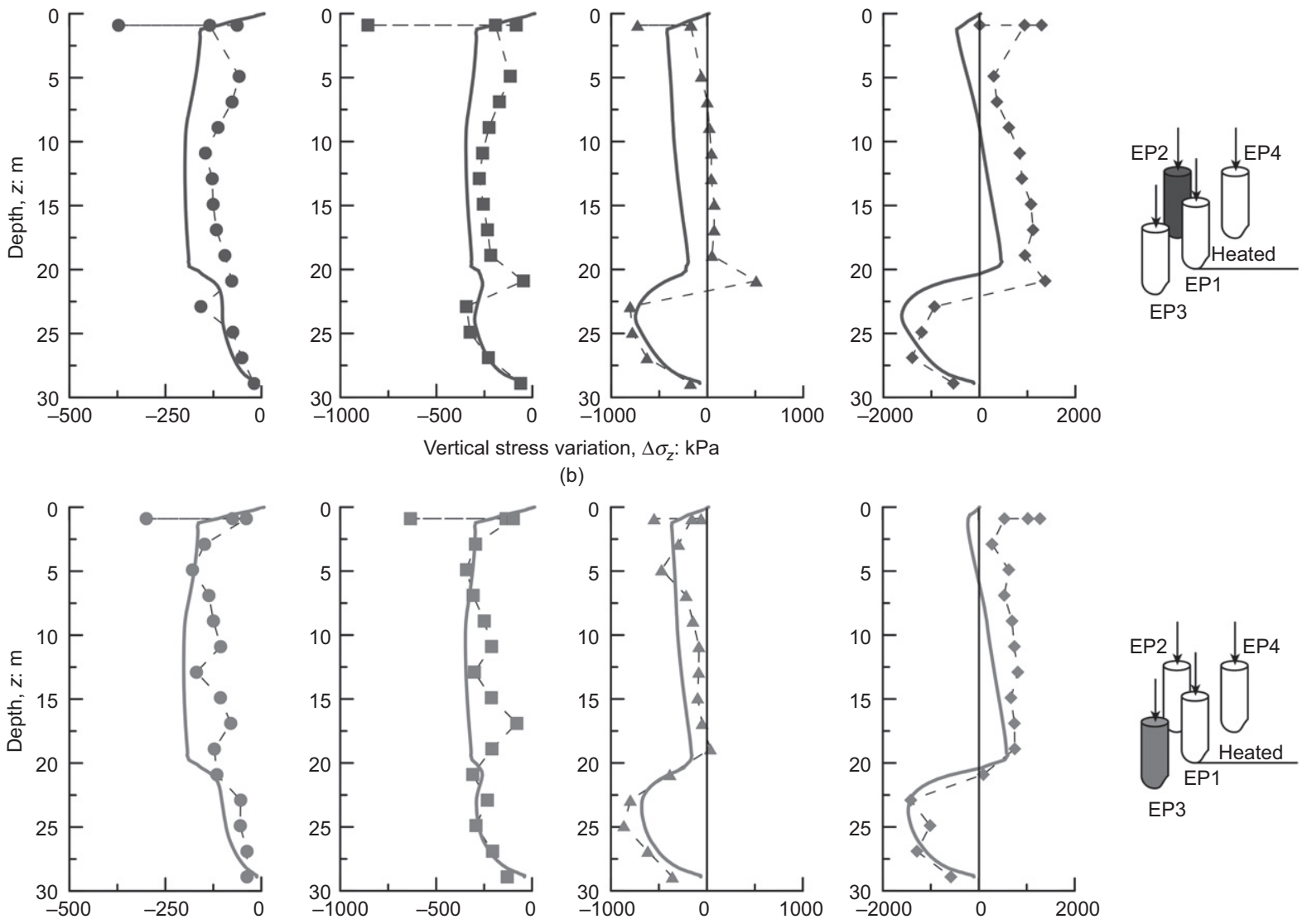

(b)
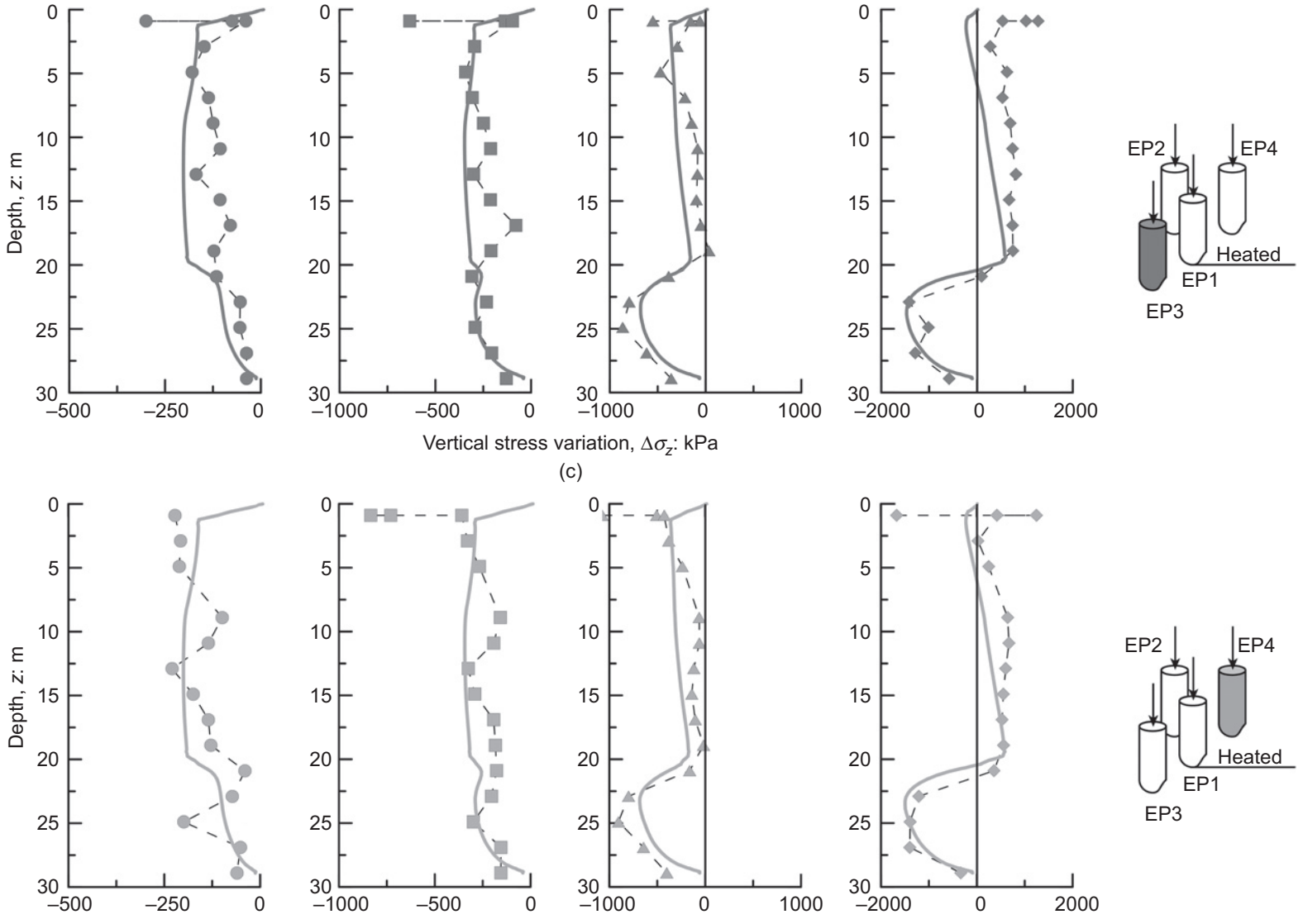

(c)
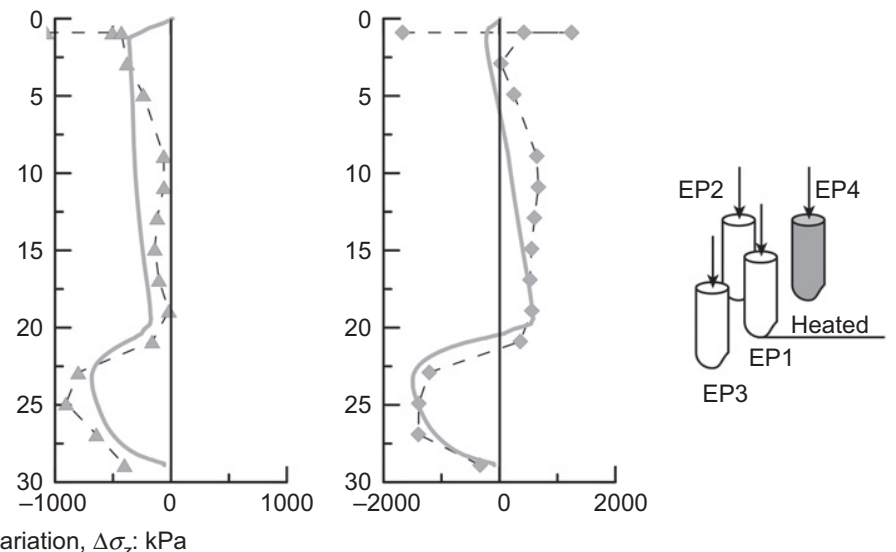

(d)

Fig. 10. Comparison between experimental and numerical vertical stress variations observed along (a) the operating energy pile EP1 and (b), (c), (d) the non-operating energy piles EP2, 3 and 4, after $t=2,8,35$ and 156 days of testing 
higher negative values in their bottom portions. Similar results were obtained by the numerical analysis.

The effect of the more pronounced thermally induced deformation of the molasse layer than the deformation in the bottom portions of the piles was again evident during the successive stages of the heating phase of energy pile EP1. The deformation of this layer pulled both the operating energy pile EP1 and the non-operating energy piles EP2, 3 and 4 and caused the reductions of the positive thermally induced stress fields that were measured along the bottom portions of all of the piles. Because EP1 was directly heated and the positive thermally induced stress variation in this element was more pronounced than the negative stress variation that was exerted by the molasse, a positive stress field governed this pile. Because EP2, 3 and 4 were indirectly heated and the positive thermally induced stress variations in these elements were smaller than the negative stress variations that were exerted by the molasse, a negative stress field governed the bottom portions of these piles.

Together with the aforementioned phenomena, the presence of the slab played a crucial role in the variation of the stress fields in all the piles. The reason is because the deformation of the slab, which was caused by the thermally induced deformation of EP1 and the soil, resulted in an imposed deformation on EP2, 3 and 4 that caused stress variations in these elements. This phenomenon occurred as a consequence of $(a)$ the continuity and compatibility of the displacements characterising the piles, the soil and the slab as perfectly jointed solids, and $(b)$ the role of the slab as a constant stiffness boundary condition for the pile-soil system (which, differently to a constant load boundary condition, involves a load variation - and thus a stress variation - for a displacement variation in deformation-related problems). The bending rigidity per unit area of the slab is $D_{\mathrm{b}}=\left(E_{\text {slab }} t_{\text {slab }}^{3}\right) /\left[12\left(1-v_{\text {slab }}^{2}\right) B_{\text {slab }} L_{\text {slab }}\right]=10080 \mathrm{kN} / \mathrm{m}$ where $E_{\text {slab }}$ and $v_{\text {slab }}$ are the Young's modulus and Poisson ratio of the slab, respectively, and $B_{\text {slab }}, L_{\text {slab }}$ and $t_{\text {slab }}$ are the breadth, length and thickness of the slab, respectively.

Vertical stress variations at the toe of the operating energy pile Figure 11 shows the vertical stress variations that were determined experimentally through the readings of the pressure cell at the toe of the operating energy pile EP1 and numerically through the finite-element model.

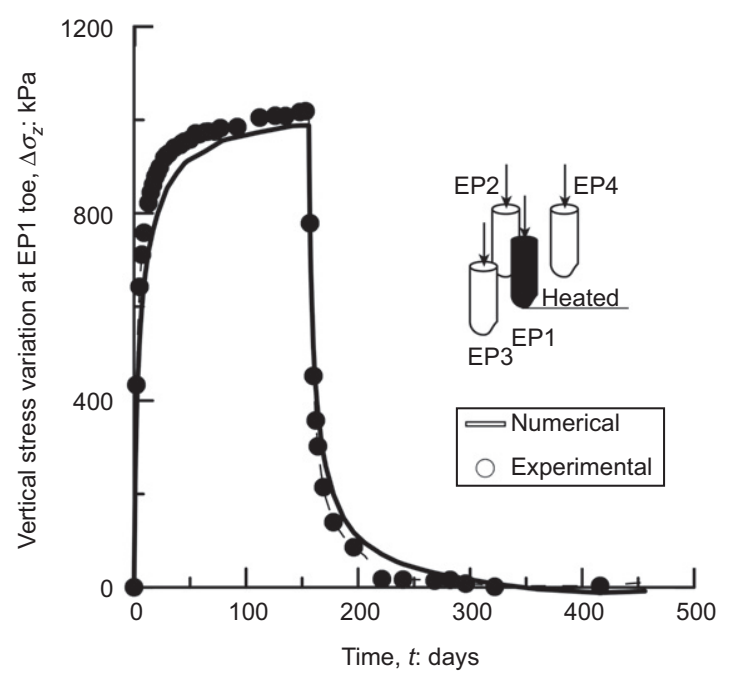

Fig. 11. Comparison between experimental and numerical vertical stress variations observed at toe of operating energy pile EP1 with time
A remarkable increase of the compressive stress was observed at the toe of EP1 within the first month of geohermal operation in both the experimental and numerical results. The vertical stress increased along with the observed increase of temperature due to the restrained thermal expansion of the pile. Less pronounced increases of the vertical stress were observed experimentally and numerically at the toe of the operating energy pile EP1 over time during its heating phase to the asymptotic value of approximately $\Delta \sigma_{z}=1000 \mathrm{kPa}$. This phenomenon was attributed to $(a)$ the progressively approaching steady-state thermal conditions in the system that involved a smaller development (and restraint) of thermally induced deformation of the pile and (b) the pulling (i.e. relieving) thermally induced action that was exerted by the molasse around the bottom portion of the pile. At the end of the test, the toe of the operating energy pile EP1 was unloaded by the increase of the compressive stress that was described above. This phenomenon was observed in both the experimental and numerical results.

\section{Variations of radial strain in the operating energy pile}

Figure 12 shows the variations in radial strain that were determined experimentally through the readings of an optical fibre that was mounted along the reinforcing cage of the operating energy pile EP1 at a depth of $z=9 \mathrm{~m}$ and numerically through the finite-element model. The trend of radial strain under free thermal expansion conditions that was calculated based on the point value of temperature change recorded by a thermocouple at $z=8.9 \mathrm{~m}$ is also plotted for reference. The numerical results refer to an average of the strain variations of ten points that were selected in the numerical model along the circumference representing the reinforcing cage placed in EP1 in the real case.

A progressive increase in the variation of the expansive strain was observed with time during the heating phase of energy pile EP1 because of the positive temperature change observed in the considered element. A maximum variation in the expansive radial strain of $\Delta \varepsilon_{\mathrm{r}}=-130 \mu \varepsilon$ was observed after $t=156$ days in both the experimental and numerical results. The variation of the expansive strain that was observed experimentally and numerically throughout the heating phase of energy pile EP1 was smaller than that calculated under free thermal expansion conditions. This condition did not hold toward the end of the passive cooling phase of EP1. Such a phenomenon can be attributed to the different average temperature change characterising the cross-section of EP1 at a depth of $z=9 \mathrm{~m}$ compared to the punctual value of temperature change recorded at $z=8.9 \mathrm{~m}$ by the thermocouple.

\section{DISCUSSION}

Comparison between the Class $B 1$ and $C 1$ prediction results

Figure 13 shows the comparison between the variations in vertical strain that were determined through the Class B1 and final Class $\mathrm{C} 1$ numerical predictions along the lengths of energy piles EP1 and 2. The experimental results are plotted for reference. The role of the different values of thermal expansion coefficient used for characterising the layers $\mathrm{B}, \mathrm{C}$ and $\mathrm{D}$ in the Class $\mathrm{B} 1$ and $\mathrm{C} 1$ predictions on the thermally induced mechanical behaviour of the foundation is shown.

At the early stages of the heating phase of energy pile EP1, a small difference between the variations in vertical strain that were determined through the numerical analyses was observed and the results agreed well with the experimental observations. At these stages, a limited volume of soil was 


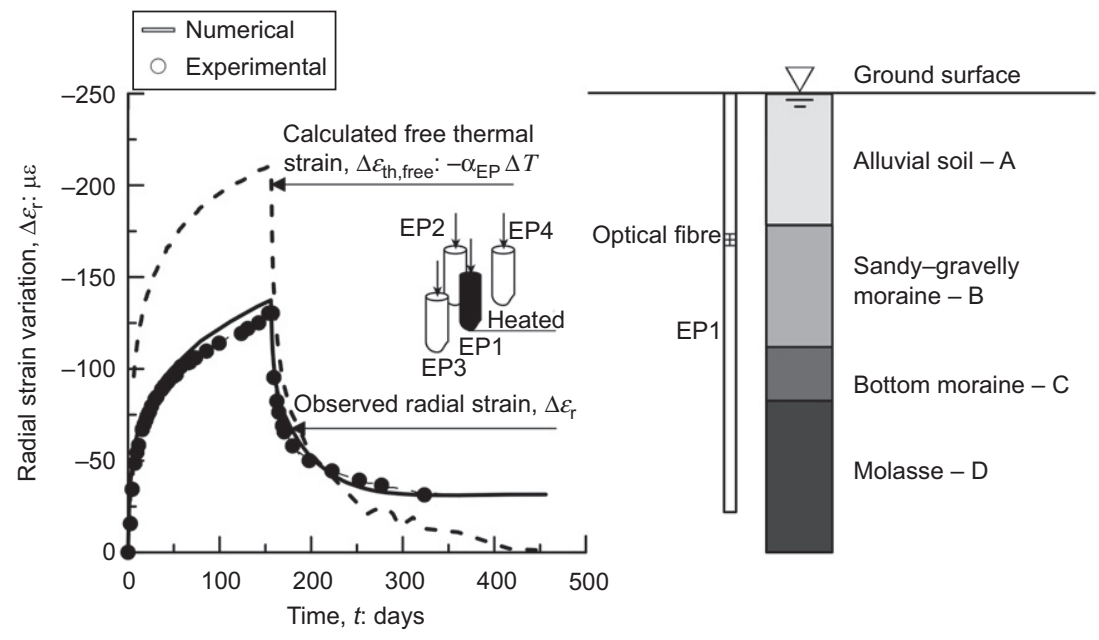

Fig. 12. Comparison between experimental and numerical radial strain variations observed at a depth of $z=9 \mathrm{~m}$ in operating energy pile EP1 with time
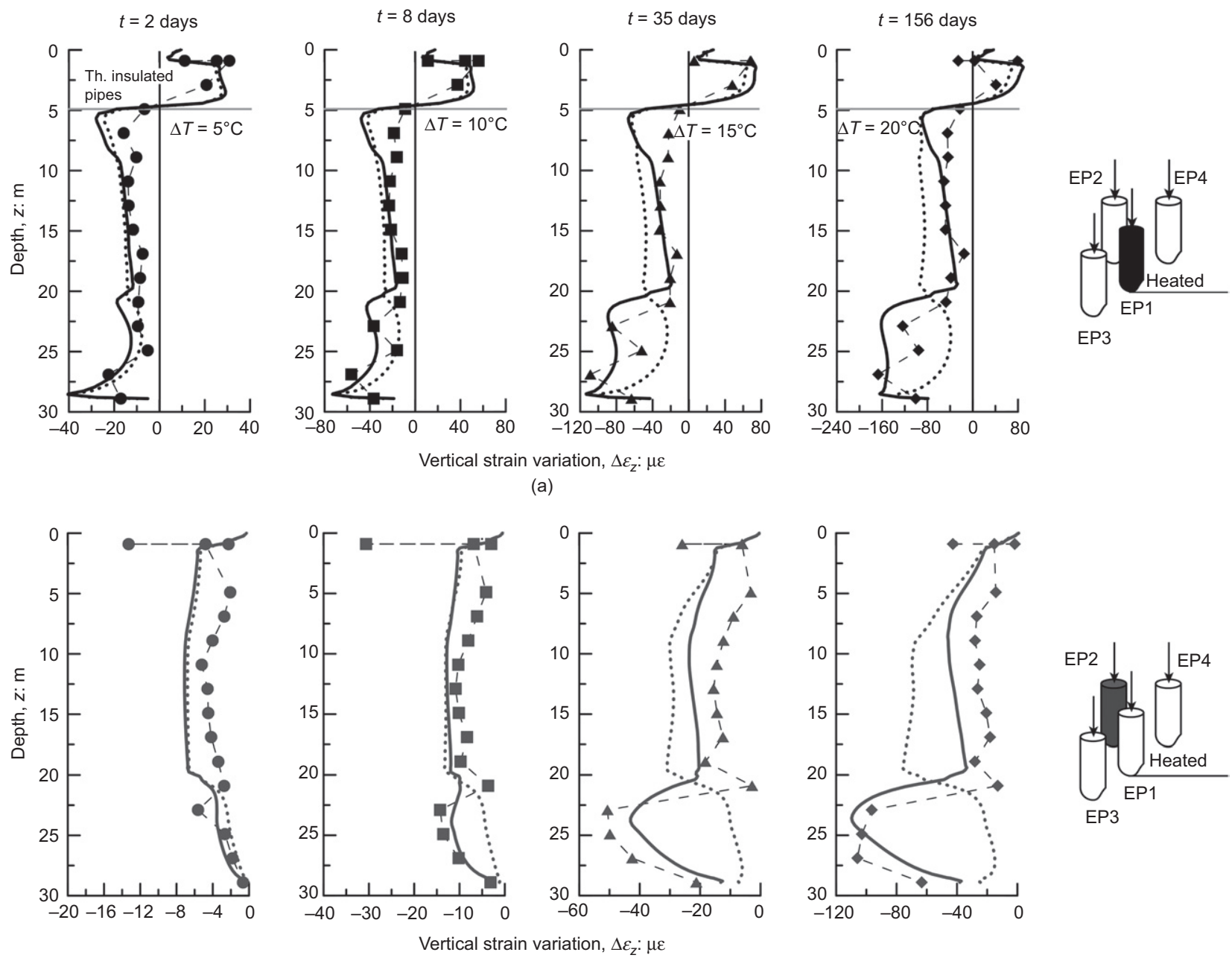

(b)

O Experimental $\quad \cdots \cdots . .$. Class B1 numerical prediction Class $\mathrm{C} 1$ numerical prediction

Fig. 13. Comparison between variations in vertical strain observed through Class $B 1$ and $C 1$ numerical predictions and the experimental test along (a) the operating energy pile EP1 and (b) the non-operating energy pile EP2, after $t=2,8,35$ and 156 days of testing

subjected to a temperature change. Thus, despite the different values of thermal expansion coefficient used in the Class B1 and $\mathrm{C} 1$ predictions, the thermally induced deformation of the soil was limited and a small impact of the deformation of this material on that of both the operating and non-operating energy piles was observed.
At the successive stages of the heating phase of energy pile $\mathrm{EP} 1$, an increasing difference between the variations in vertical strain that were estimated through the numerical analyses was noted. The results of the Class $\mathrm{B} 1$ prediction indicated an opposite evolution in vertical strain along the lengths of the energy piles compared to the experimental observations and, 
at a later stage, of the Class $\mathrm{C} 1$ prediction results. In general, greater variations in vertical strain were observed in the layers characterised by the greater thermal expansion coefficients. Greater strain variations were determined in the shallower portions of the energy piles by the Class B1 prediction compared to the smaller variations determined experimentally and by the Class $\mathrm{C} 1$ prediction. Smaller strain variations were determined in the deeper portions of the energy piles by the Class B1 prediction compared to the greater variations determined experimentally and by the Class $\mathrm{C} 1$ prediction. Marked differences between the variations in vertical stress along the lengths of all of the energy piles resulted as a consequence of this occurrence. The reason for the observed difference between the Class $\mathrm{B} 1$ prediction results and the experimental and Class $\mathrm{C} 1$ prediction results is because at the successive stages of the heating phase of energy pile EP1, a noteworthy volume of soil was subjected to a temperature change. This phenomenon involved a thermally induced deformation of the soil with a marked impact on the variation of the deformation of both the operating and non-operating energy piles. Thus, the use in the Class B1 prediction of unsuitable values of thermal expansion coefficient for characterising layers $\mathrm{B}, \mathrm{C}$ and $\mathrm{D}$ resulted in the differences described above. This fact highlights the essential role of a thorough estimation of the thermal expansion coefficient of the materials involved in energy pile-related problems for obtaining representative results of reality through any kind of prediction performed (e.g. Class A predictions).

\section{Key aspects governing the behaviour of energy pile groups}

The results that were described in the previous sections demonstrate that the behaviour of groups of closely spaced energy piles that operate partially as geothermal heat exchangers over timescales that are typical of practical applications is characterised by significant thermally induced group effects. These group effects are evidenced through thermal and thermally induced mechanical interactions between the operating and non-operating energy piles, the soil and the slab.

Thermal interactions appear during successive stages of geothermal operations. For the same geometrical features of the pile group (e.g. the length of the piles and the centreto-centre spacing between the piles) and a given thermal load applied to the operating energy piles, the magnitude and development of these interactions are governed by $(a)$ the energy design solutions characterising the operating energy piles (e.g. the pipe configuration, the mass flow rate of the fluid circulating in the pipes and the fluid mixture composition), and (b) the thermal and hydraulic properties of the foundation. These interactions were not observed by Mimouni \& Laloui (2015) because of the short duration of their tests, but are considered to be important for the analysis and design (e.g. geotechnical, structural and energy) of these foundations.

Thermally induced mechanical interactions are always present throughout the geothermal operations. For the same geometrical features of the pile group (e.g. the length of the piles and the centre-to-centre spacing between the piles) and a given thermal load applied to the operating energy piles, the magnitude and development of these interactions are governed by $(a)$ the relative amount of thermally induced deformation of soil to pile per unit temperature change, $(b)$ the relative stiffness of slab to soil and $(c)$ the relative stiffness of pile to soil. These characteristics of energy pile groups can be classified through three dimensionless ratios, as listed below.

(a) The soil-pile thermal expansion coefficient ratio

$$
X=\frac{\alpha_{\text {soil }}}{\alpha_{\mathrm{EP}}}
$$

where $\alpha_{\text {soil }}$ is the linear thermal expansion coefficient of the soil. The soil-pile thermal expansion coefficient ratio allows the roles of the thermally induced deformations of the soil and the piles in the deformation of the energy pile group to be envisaged at successive stages of geothermal operations. Values of $X>1$ correspond to a deformation of the energy pile group governed by the thermally induced deformation of the soil surrounding the piles, whereas values of $X \leq 1$ correspond to a deformation of the energy pile group governed by the thermally induced deformation of the piles (Bourne-Webb et al., 2016). Practical ranges of $X$ are between $0 \cdot 1$ and 4 . According to the findings provided by Bourne-Webb et al. (2016) for single isolated energy piles, the spatial extent of the field that involves temperature variations in the soil around the energy piles governs the effect of $X$ on the thermally induced deformation of the energy pile group. The greater the volume of soil subjected to a temperature change is, the more pronounced is the relative deformation between the energy piles and the soil.

(b) The slab-soil stiffness ratio

$$
K_{\text {ss }}=\frac{4 E_{\text {slab }} B_{\text {slab }} t_{\text {slab }}^{3}\left(1-v_{\text {soil }}^{2}\right)}{3 \pi E_{\text {soil }} L_{\text {slab }}^{4}\left(1-v_{\text {slab }}^{2}\right)}
$$

where $E_{\text {soil }}$ and $v_{\text {soil }}$ are the Young's modulus and the Poisson ratio of the soil, respectively. The definition of this ratio is based on the work of Brown (1975) for the analysis of strip footings. It was formulated and exploited by Clancy \& Randolph (1996) for the analysis of slabs connecting conventional piles and is extended herein to the analysis of slabs connecting energy piles. The slab-soil stiffness ratio allows estimation of the impact of the presence of the slab on the load and displacement redistributions in the energy pile group. Values of $K_{\mathrm{ss}} \approx 0 \cdot 001$ correspond to a flexible slab, whereas values of $K_{\mathrm{ss}} \approx 0 \cdot 1$ correspond to an almost rigid slab (Brown, 1975). Practical ranges of $K_{\mathrm{ss}}$ are between 0.001 and 10 (Clancy \& Randolph, 1996).

(c) The pile-soil stiffness ratio

$$
\Lambda=\frac{E_{\mathrm{EP}}}{G_{\text {soil }}}
$$

where $G_{\text {soil }}$ is the shear modulus of the soil. The definition of this ratio is based on the work of Randolph \& Wroth (1978) for the analysis of conventional piles subjected to solely mechanical loads and is extended herein to the analysis of energy pile groups subjected to both mechanical and thermal loads. It considers the shear modulus of the soil (which is preferred to the Young's modulus) because in pile-related problems the soil deforms primarily in shear and because the shear modulus is usually assumed to be unaffected by whether the loading is drained or undrained. The pile-soil stiffness ratio characterises the load-displacement relationship between each of the single piles in the group and the surrounding soil. Values of $\Lambda \approx 10$ correspond to a compressible pile, whereas values of $\Lambda \approx 10000$ correspond to an almost rigid pile (Poulos \& Davis, 1980). Practical ranges of $\Lambda$ are between 100 and 10000 (Randolph \& Clancy, 1993).

Significant attention must be paid to the thermally induced mechanical interactions because they are important in the analysis and design (e.g. geotechnical and structural) of energy pile groups. 
Design considerations for energy pile groups

Significant positive vertical stress variations (i.e. increases in compressive stress compared to the change that is induced by the superstructure's mechanical loads) were observed in the operating energy pile. These vertical stress variations (up to $\Delta \sigma_{z}=5500 \mathrm{kPa}$ ) are greater than those that were numerically estimated to be induced by the applied superstructure mechanical loads in both the operating and non-operating energy piles (see Fig. 14). Based on the characteristic compressive strength of the concrete that was used in this study - a higher-than-typical class of compressive strength of concrete was conservatively used for the energy piles based on the experiments foreseen - (e.g. $\left.f_{\mathrm{ck}}=45 \mathrm{MPa}\right)$, the observed compressive vertical stress variations are not considered to be an issue for the structural integrity of the pile. Although the temperature change that was induced in the operating energy pile in this study is significant, and the features of the foundation are favourable for the development of large compressive vertical stress variations (e.g. compared to a floating pile foundation), worse conditions cannot be discounted (stiffer bearing soil layers and slab). Thus, the vertical stress variations that are induced by temperature changes in operating energy piles should be considered throughout the structural design of energy pile groups that partially and entirely operate as geothermal heat exchangers (with reference, e.g. to the serviceability limit state).

Notable negative vertical stress variations (i.e. decreases in compressive stress compared to the variation that is induced by the superstructure's mechanical loads) were observed in the non-operating energy piles because of the thermally induced group effects. The absolute values of these vertical stress variations (up to $\Delta \sigma_{z}=-1419 \mathrm{kPa}$ ) are comparable to those that were numerically estimated to be induced by the superstructure's mechanical loads in these elements (see Fig. 14). These results indicate that tensile stresses do not develop, and such stress variations are not considered to be an issue for the structural integrity of the piles in this study. However, cases that utilise greater numbers of operating energy piles than in this study are common and may be a concern especially with reference to non-operating energy piles characterised by low or null values of applied mechanical loads. Thus, the vertical stress variations in nonoperating energy piles as a result of the thermally induced deformation of operating energy piles should be considered

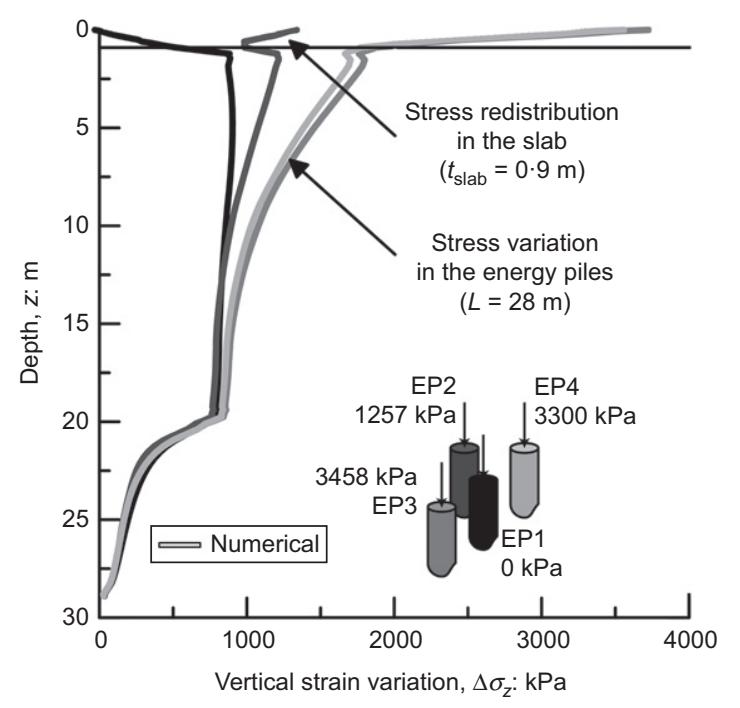

Fig. 14. Numerical vertical stress variations induced by the superstructure's mechanical loads along energy piles EP1, 2, 3 and 4 (the stress distributions that are associated with the in situ conditions have been subtracted) throughout the structural design of groups of such foundations (with reference, e.g. to the serviceability limit state).

Finally, significant vertical displacement variations were observed in both the operating and non-operating energy piles. As shown in Fig. 15, these changes in vertical displacement, which were determined from the numerical analysis, are greater than those that were induced by the superstructure's mechanical loads. The superstructure's mechanical loads were initially found to induce pile settlements of up to $\Delta w=0.98 \mathrm{~mm}$. At the end of the heating phase of energy pile EP1, the temperature changes in the foundation were found to induce pile heaves of up to $\Delta w=-1 \cdot 10 \mathrm{~mm}$. The thermally induced displacements were thus up to double those that were induced by the superstructure's mechanical loads. The observed displacement variations are not critical under current European design standards (EN 1997 (BSI, 2004)) for serviceability conditions. They may, however, represent a concern for a greater number of operating energy piles. This consideration appears to be particularly relevant for piles characterised by a prevalent end-bearing character, surrounded by soft soil deposits and connected to remarkably flexible slabs. For this reason, the vertical displacements that are induced by temperature changes in operating and non-operating energy piles should be considered throughout the structural and geotechnical designs of energy pile groups (with reference, e.g. to the serviceability limit state).

\section{Suitability and limitations of using thermo-elasticity for simulating energy pile groups}

Analyses that are based on linear elasticity theory have been shown to successfully reproduce the mechanical behaviour of an extensive number of conventional pile groups subjected to mechanical loads of limited magnitude (e.g. Poulos \& Davis, 1980; Fleming et al., 2008). Similarly, analyses that are based on linear thermo-elasticity theory appear to be suitable for reproducing the thermo-mechanical behaviour of energy pile groups subjected to mechanical and thermal loads of limited magnitude. With the term 'limited', reference is made to the magnitudes of mechanical and thermal loads, the combined action of which involves effects that are far from inducing the geotechnical and/or structural failure (ultimate limit state) of the pile/s, and are characteristic of the serviceability limit state. In other words, reference is made to loads for which the induced effects are reversible (i.e. elastic). Under these conditions, this statement appears to be valid for both monotonic and cyclic thermal loads that are applied to the energy piles.

The capability of linear thermo-elasticity theory to describe the behaviour of energy piles such as the end-bearing group that was analysed in this study is corroborated by the reversible response that was found experimentally to characterise the operating energy pile EP1 throughout the test. This is shown in Fig. 16(a), which depicts the experimental and numerical distribution of vertical strain along the operating energy pile EP1 for an average temperature change of $\Delta T=5^{\circ} \mathrm{C}$ that was observed along the uninsulated portion of this pile during the heating and passive cooling phases of the test. Figure 16(b) presents the evolution of this temperature change along the length of EP1. The differences between the strain curves (especially in the molasse layer) are attributed to the different thermal field that was observed experimentally and numerically to characterise the soil, the non-operating energy piles EP2, 3 and 4, and the operating energy pile EP1 when this latter pile was subjected to the same average temperature change during the heating and passive cooling phases of the test. Residual temperature changes were observed during the late stages of the passive 


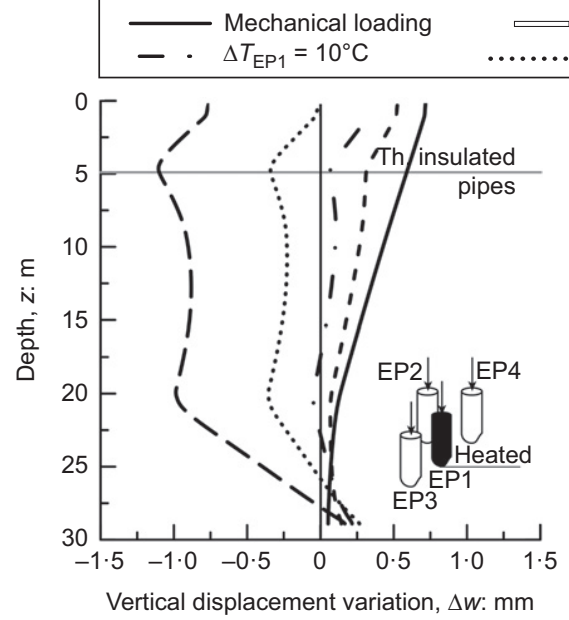

(a)

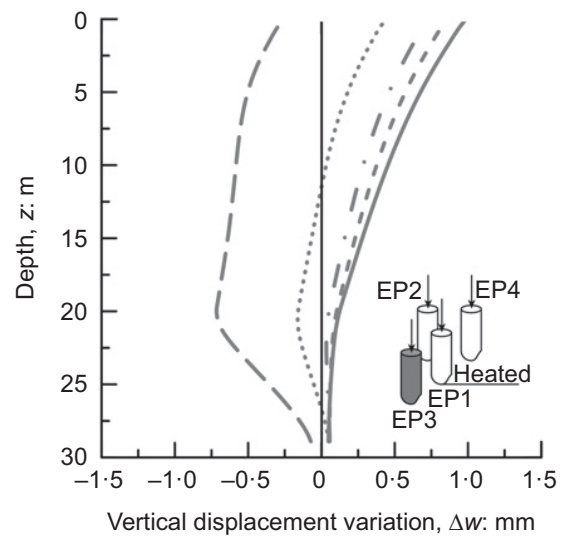

(c) $\begin{array}{ll}\text { Numerical } & --\Delta T_{\mathrm{EP} 1}=5^{\circ} \mathrm{C} \\ \Delta T_{\mathrm{EP} 1}=15^{\circ} \mathrm{C} & -\Delta T_{\mathrm{EP} 1}=20^{\circ} \mathrm{C}\end{array}$

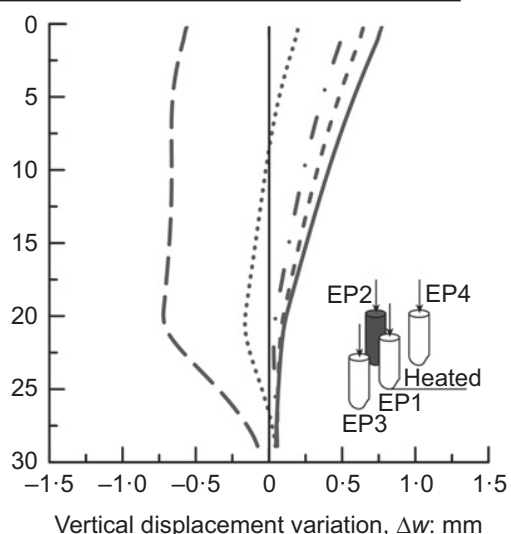

(b)

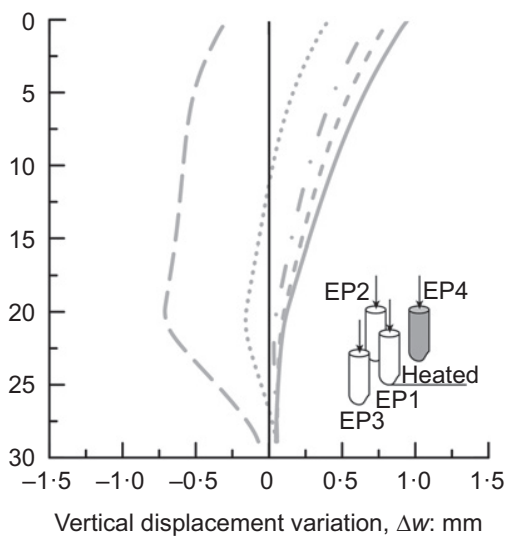

(d)

Fig. 15. Numerical vertical displacement variations induced by the superstructure's mechanical loads and temperature changes along energy piles EP1, 2, 3 and 4 (the displacement distributions that are associated with the in situ conditions have been subtracted)

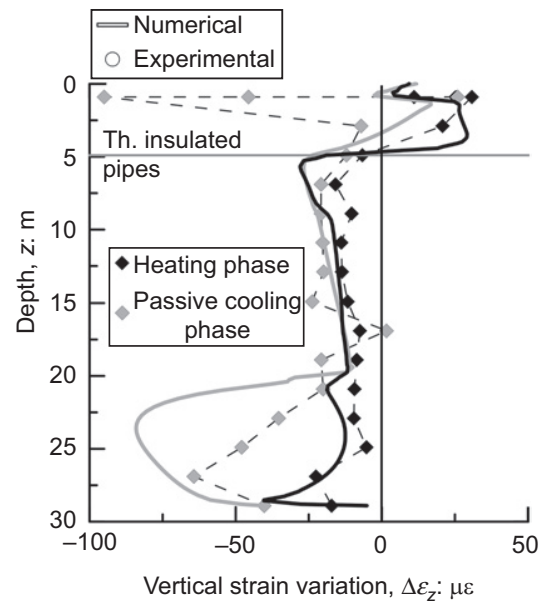

(a)

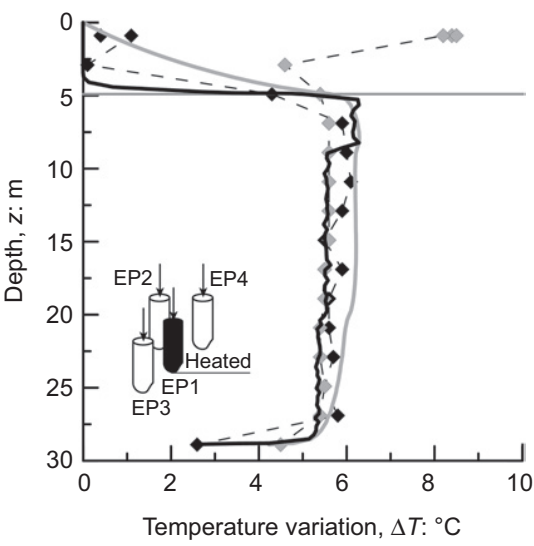

(b)

Fig. 16. Experimentally and numerically observed (a) vertical strain variations along the operating energy pile EP1 for (b) approximately the same average temperature change that was recorded with depth during the heating and passive cooling phases of the test

cooling of EP1 in a number of regions of the pile group. These temperature changes involved thermally induced expansions of the materials that caused a residual deformation of the energy pile group (and thus, of EP1) with reference to the initial condition. The differences between the experimental and numerical curves referred to the same phase of the test (especially in the molasse layer) are caused by differences in the temperature fields characterising the energy pile group in the real case and in the numerical model.

The suitability of linear thermo-elasticity for the analysis of end-bearing energy piles such as the group that was analysed in this study is extended to other testing conditions and sites based on the experimental observations of Murphy et al. (2015), Mimouni \& Laloui (2015) and Wang et al. (2014) as well as the numerical results of Di Donna et al. 
(2016). Linear thermo-elasticity appears to be suitable also for the analysis of groups of friction energy piles.

When dealing with situations in which significant magnitudes of mechanical and thermal loads are applied to energy pile groups, careful judgement on the suitability of a linear thermo-elastic approach of analysis has to be considered. The inappropriate use of thermo-elasticity theory may involve marked pitfalls in the analysis and/or design of energy pile groups because of differences between the actual and modelled mechanical behaviours of the piles and surrounding soil. This comment appears to be particularly relevant for groups of friction energy piles. The reason is that, for the same applied load, friction energy piles mobilise a greater proportion of shear stress at the pile-soil interface compared to end-bearing energy piles. This distribution of shear stress may be associated to plastic strain at the pile-soil interface. Notable variations in the behaviour of friction
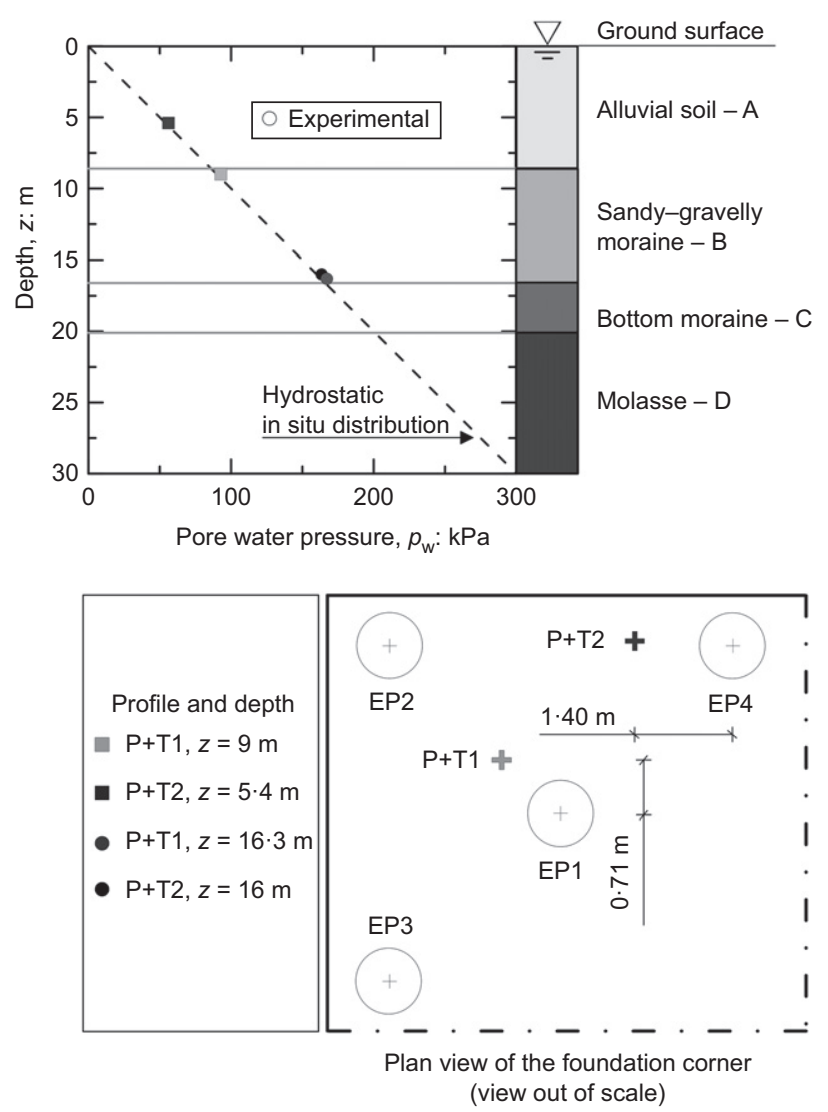

Fig. 17. Maximum experimentally observed pore water pressure variations along profiles $P+T 1$ and $P+T 2$ in the soil energy piles may consequently arise because of the marked sensitivity of these foundations to the response of the pile-soil interface (Rotta Loria et al., 2015). These variations may increase for cyclic thermal loads applied to the piles with time (Di Donna \& Laloui, 2014; Ng et al., 2014; Yavari et al., 2014; Saggu \& Chakraborty, 2015; Suryatriyastuti et al., 2015; Ng et al., 2016; Vieira \& Maranha, 2016), such a consideration suggesting the unsuitability of an elastic approach of analysis in those situations. Thermo-elastic analyses can be considered unsuitable also for situations that involve mechanisms and phenomena inducing plastic strain in the soil surrounding the piles irrespective of the magnitude of the applied loads. Situations that involve energy piles socketed in normally consolidated clayey soils are a key example because the responses of these soils to heating have been shown to be inelastic (Campanella \& Mitchell, 1968; Plum \& Esrig, 1969; Demars \& Charles, 1981; Baldi et al., 1988; Hueckel \& Baldi, 1990; Burghignoli et al., 2000; Cekerevac \& Laloui, 2004; Vega \& McCartney, 2014; Di Donna \& Laloui, 2015).

\section{Suitability and limitations of using thermo-mechanical analyses for simulating energy pile groups}

The use of thermo-mechanical analyses to reproduce the thermo-mechanical behaviour of energy pile groups that are subjected to mechanical and thermal loads in saturated soil deposits without intrinsic groundwater flow appears to be suitable in most applications.

This consideration is corroborated with reference to the analysed test by the negligible variation of the hydraulic field experimentally determined through the readings of the piezometers and of the thermistors in the soil. This phenomenon can be noted referring to Figs 17 and 18, which show the maximum pore water pressures that were observed throughout the test along soil profiles $\mathrm{P}+\mathrm{T} 1$ and $\mathrm{P}+\mathrm{T} 2$, and the trends of pore water pressure variations at selected points along soil profiles $\mathrm{P}+\mathrm{T} 1$ and $\mathrm{P}+\mathrm{T} 2$, respectively. Negligible pore water pressure variations were also observed to characterise the site considered by Mimouni \& Laloui (2015) and Di Donna et al. (2016) based on experimental and numerical results, respectively. Di Donna et al. (2016) further noted a negligible variation of the hydraulic field in soil layers of low intrinsic permeability and coefficient of compressibility of the solid particles forming the skeleton that were subjected to even higher magnitudes and rates of temperature changes than those in this study. Yet, Di Donna et al. (2016) observed that the magnitude of the pore water pressure variations characterising $\mathrm{P}+\mathrm{T} 1$ and $\mathrm{P}+\mathrm{T} 2$ was comparable to that numerically estimated in the region of soil adjacent to the operating energy pile/s (i.e. the pile-soil interface/s). Based on this consideration and the results

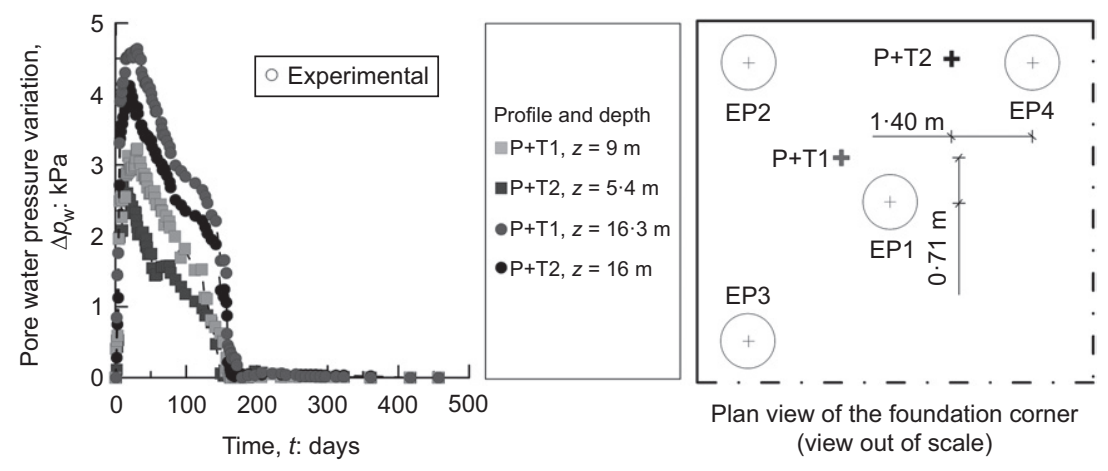

Fig. 18. Experimentally observed pore water pressure variations at selected points along profiles $P+T 1$ and $P+T 2$ with time 
presented in Figs 17 and 18, it appears justified to suppose negligible pore water pressure variations at the pile-soil interface/s in the considered experiment; that is, drained conditions are preserved upon heating.

The use of thermo-hydro-mechanical analyses can be considered essential for situations that involve energy pile groups that are subjected to mechanical and thermal loads in saturated soil deposits with intrinsic groundwater flow or characterised by remarkably low intrinsic permeability and coefficient of compressibility (e.g. values of intrinsic permeability lower than $1 \times 10^{-17} \mathrm{~m}^{2}$ and coefficient of compressibility of the solid particles forming the skeleton lower than $2 \cdot 5 \times 10^{-10} 1 / \mathrm{Pa}$ based on the results of numerical analyses performed by the authors). In the former case, differences between the actual and modelled thermal behaviour of the operating energy piles may arise irrespective of the magnitude of the applied loads because of the preponderant convective character of the heat exchange process. In the latter case, differences between the actual and modelled mechanical behaviour of both the operating and non-operating energy piles may arise as a consequence of the application of high magnitudes of mechanical and thermal loads because of the induced variation in the hydraulic field (effective stress concept).

\section{CONCLUDING REMARKS}

This study experimentally and numerically investigated the thermally induced group effects of closely spaced energy piles that partially operate as geothermal heat exchangers over a timescale that is typical of practical applications. Some of the main conclusions that can be drawn from this work are listed below.

- Thermal interactions between operating and non-operating energy piles occur during successive stages of geothermal operations. For the same geometrical features of the pile group (e.g. the length of the piles and the centre-to-centre spacing between the piles) and a given thermal load applied to the operating energy piles, these interactions are governed by $(a)$ the energy design solutions characterising the operating energy piles (e.g. the pipe configuration, the mass flow rate of the fluid circulating in the pipes and the fluid mixture composition) and (b) the thermal and hydraulic properties of the foundation.

- Thermally induced mechanical interactions are always present throughout geothermal operations. For the same geometrical features of the pile group (e.g. the length of the piles and the centre-to-centre spacing between the piles) and a given thermal load applied to the operating energy piles, these interactions are governed by $(a)$ the relative amount of thermally induced deformation of soil to pile per unit temperature change (i.e. the soil-pile thermal expansion coefficient ratio), $(b)$ the relative stiffness of slab to soil (i.e. the slab-soil stiffness ratio), and $(c)$ the relative stiffness of pile to soil (i.e. the pile-soil stiffness ratio). The thermal field characterising the foundation governs the magnitude and impact of aspect (a) on the development of thermally induced mechanical interactions.

- Thermal and thermally induced mechanical interactions are considered to be important for the analysis and design (e.g. geotechnical, structural and energy) of energy pile groups.

- Significant stress, strain and displacement variations are induced in both the operating and non-operating energy piles by all of these interactions. These vertical stress, strain and displacement variations are not critical for the serviceability performance of the piles tested in this study. However, attention must be devoted to these phenomena throughout the design process (e.g. geotechnical and structural) of energy pile groups at the serviceability limit state. Their magnitudes can be comparable to and even higher than those of the superstructure mechanical loads.

- Linear thermo-elasticity theory appears to be an expedient and sufficiently accurate tool to describe the geotechnical and structural behaviour of a wide number of energy pile groups for both research and engineering purposes.

- Thermo-mechanical numerical analyses appear to be suitable tools for modelling the geotechnical, structural and energy behaviour of most energy pile groups surrounded by saturated soil deposits without intrinsic groundwater flow. Consideration of the pipes-pile-soil system appears to be important to modelling the energy behaviour of energy pile groups because it allows the thermo-mechanical response of the energy piles with a phase shift to be reproduced for a variety of boundary conditions.

\section{ACKNOWLEDGEMENTS}

The authors are grateful to Mr Patrick Dubey, Mr Swann Brede and Mr Bastien Pasquier for their help in recording the experimental data during the in situ test. Mr Niccolò Batini and Ms Perrine Ratouis are acknowledged for their efforts in constructing a series of preliminary versions of the numerical model that was used in this study. The help with the experimental equipment that was provided by Dr Thomas Mimouni is highly appreciated. Dr Alice Di Donna is acknowledged for fruitful discussions about the challenging problem that was addressed in this work. Discussions with Dr Victor Vilarrasa during the Class $\mathrm{C} 1$ prediction process helped to obtain realistic numerical results and were much appreciated. The financial support of the Swiss National Science Foundation (project no. 160117, Division I-III) is acknowledged.

$\begin{aligned} & \text { NOTATION } \\ & B_{\mathrm{slab}} \text { breadth of slab } \\ & c_{\mathrm{p}, \mathrm{s}} \text { specific heat of solid particles } \\ & D \text { diameter of pile } \\ & D_{\mathrm{b}} \text { bending rigidity of slab } \\ & E \text { Young's modulus } \\ & f_{\mathrm{ck}} \text { characteristic compressive strength } \\ & G \text { shear modulus } \\ & K_{\mathrm{ss}} \text { slab-soil stiffness ratio } \\ & K_{0} \text { coefficient of earth pressure at rest } \\ & L \text { length of pile } \\ & L_{\text {slab }} \text { length of slab } \\ & n \text { porosity } \\ & P \text { mechanical load } \\ & p_{\mathrm{w}} \text { pore water pressure } \\ & T \text { actual temperature } \\ & T_{\text {bulk,f,in }} \text { inflow temperature of fluid circulating in the pipes } \\ & T_{\mathrm{bulk}, \mathrm{f}, \mathrm{out}} \text { outflow temperature of fluid circulating in the pipes } \\ & T_{0} \text { initial temperature } \\ & t \text { time } \\ & t_{\mathrm{slab}} \text { thickness of slab } \\ & u_{\mathrm{f}} \text { velocity of fluid circulating in the pipes } \\ & w \text { vertical displacement } \\ & X \text { soil-pile thermal expansion coefficient ratio } \\ & z \text { depth or vertical coordinate } \\ & \alpha \text { linear thermal expansion coefficient } \\ & \varepsilon_{\mathrm{th}, \text { free }} \text { strain under free thermal expansion conditions } \\ & \varepsilon_{\mathrm{r}} \text { radial strain } \\ & \varepsilon_{z} \text { vertical strain }\end{aligned}$

\section{NOTATION}

$C_{\mathrm{ps}}$ specific heat of solid particles

$D$ diameter of pile

$D_{\mathrm{b}}$ bending rigidity of slab

$E$ Young's modulus

$f_{c k} \quad$ characteristic compressive strength

shear modulus

$K_{0}$ coefficient of earth pressure at rest

$L \quad$ length of pile

of sla

$P$ mechanica

$T_{\text {bulk,fin }}$ inflow temperature of fluid circulating in the pipes

$T_{0}$ initial temperature

thickness of slab

$u_{\mathrm{f}} \quad$ velocity of fluid circulating in the pipes

$w$ vertical displacement

soil-pile thermal expansion coefficient ratio

$z$ depth or vertical coordinate

strain under free thermal expansion condition

$\varepsilon_{z} \quad$ vertical strain 


$\begin{aligned} \Lambda & \text { pile-soil stiffness ratio } \\ \lambda_{\text {eff }} & \text { effective thermal conductivity } \\ \lambda_{\mathrm{p}} & \text { thermal conductivity of pipe } \\ \lambda_{\mathrm{s}} & \text { thermal conductivity of solid particles } \\ v & \text { Poisson ratio } \\ \rho_{\mathrm{s}} & \text { density of solid particles } \\ \sigma_{z} & \text { vertical stress } \\ \phi & \text { inner diameter of pipe }\end{aligned}$

\section{REFERENCES}

Abdelaziz, S. \& Ozudogru, T. Y. (2016). Non-uniform thermal strains and stresses in energy piles. Environ. Geotech. 3, No. 4, 237-252, http://dx.doi.org/10.1680/jenge.15.00032.

Akrouch, G. A., Sánchez, M. \& Briaud, J. L. (2014). Thermo-mechanical behavior of energy piles in high plasticity clays. Acta Geotechnica 9, No. 3, 399-412.

Baldi, G., Hueckel, T. \& Pellegrini, R. (1988). Thermal volume changes of the mineral water-system in low-porosity clay soils. Can. Geotech. J. 25, No. 4, 807-825.

Batini, N., Rotta Loria, A. F., Conti, P., Testi, D., Grassi, W. \& Laloui, L. (2015). Energy and geotechnical behaviour of energy piles for different design solutions. Comput. Geotech. 86, No. 1, 199-213.

Bourne-Webb, P. J., Amatya, B. L., Soga, K., Amis, T., Davidson, C. \& Payne, P. (2009). Energy pile test at Lambeth College, London: geotechnical and thermodynamic aspects of pile response to heat cycles. Géotechnique 59, No. 3, 237-248, http://dx.doi.org/10.1680/geot.2009.59.3.237.

Bourne-Webb, P., Bodas Freitas, T. \& Freitas Assunção, R. (2016). Soil-pile thermal interactions in energy foundations. Géotechnique 66, No. 2, 167-171, http://dx.doi.org/10.1680/ jgeot.15.T.017.

Brown, P. (1975). Strip footing with concentrated loads on deep elastic foundations. J. Geotech. Engng 6, No. 1, 1-13.

BSI (2004). BS EN-1997: Eurocode 7: Geotechnical design. London, UK: BSI.

Burghignoli, A., Desideri, A. \& Miliziano, S. (2000). A laboratory study on the thermomechanical behaviour of clayey soils. Can. Geotech. J. 37, No. 4, 764-780.

Campanella, R. G. \& Mitchell, J. K. (1968). Influence of the temperature variations on soil behaviour. J. Soil Mech. Found. Engng Div. ASCE 94, No. SM3, 709-734.

Caulk, R., Ghazanfari, E. \& McCartney, J. S. (2016). Parameterization of a calibrated geothermal energy pile model. Geomech. Energy Environ. 5, 1-15.

Cekerevac, C. \& Laloui, L. (2004). Experimental study of thermal effects on the mechanical behaviour of a clay. Int. J. Numer. Analyt. Methods Geomech. 28, No. 3, 209-228.

Clancy, P. \& Randolph, M. (1996). Simple design tools for piled raft foundations. Géotechnique 46, No. 2, 313-328, http://dx.doi. org/10.1680/geot.1996.46.2.313.

Comsol (2014). COMSOL Multiphysics version 4.4: user's guide and reference manual. Burlington, MA, USA: Comsol.

Demars, K. R. \& Charles, R. D. (1981). Soil volume changes induced by temperature cycling. Can. Geotech. J. 19, No. 2, 188-194.

Di Donna, A. \& Laloui, L. (2014). Numerical analysis of the geotechnical behaviour of energy piles. Int. J. Numer. Analyt. Methods Geomech. 39, No. 8, 861-888.

Di Donna, A. \& Laloui, L. (2015). Response of soil subjected to thermal cyclic loading: experimental and constitutive study. Engng Geol. 190, No. 1, 65-76.

Di Donna, A., Rotta Loria, A. F. \& Laloui, L. (2016). Numerical study on the response of a group of energy piles under different combinations of thermo-mechanical loads. Comput. Geotech. 72, No. 1, 126-142.

Fleming, K., Weltman, A., Randolph, M. \& Elson, K. (2008). Piling engineering. Boca Raton, FL, USA: CRC Press.

Goode, J. III \& McCartney, J. S. (2015). Centrifuge modeling of boundary restraint effects in energy foundations. J. Geotech. Geoenviron. Engng 141, No. 8, 04015034.

Hueckel, T. \& Baldi, G. (1990). Thermoplasticity of saturated clays experimental constitutive study. J. Geotech. Engng 116, No. 12, $1778-1796$.
Jeong, S., Min, H. \& Lee, J. K. (2014). Thermally induced mechanical response of energy piles in axially loaded pile groups. Appl. Thermal Engng 71, No. 1, 608-615.

Kalantidou, A., Tang, A. M., Pereira, J. \& Hassen, G. (2012). Preliminary study on the mechanical behaviour of heat exchanger pile in physical model. Géotechnique 62, No. 11, 1047-1051, http://dx.doi.org/10.1680/geot.11.T.013.

Kramer, C. A. \& Basu, P. (2014). Performance of a model geothermal pile in sand. In Proceedings of 8th international conference on physical modelling in geotechnics (eds C. Gaudin and D. White), pp. 771-777. Boca Raton, FL, USA: CRC Press.

Laloui, L., Moreni, M., Steinmann, G., Fromentin, A. \& Pahud, D. (1999). Test en conditions réelles du comportement statique d'un pieu soumis à des sollicitations thermomécaniques, Rapport intermédiaire. Lausanne, Switzerland: Swiss Federal Office of Energy (in French).

Laloui, L., Moreni, M. \& Vulliet, L. (2003). Comportement d'un pieu bi-fonction, fondation et échangeur de chaleur. Can. Geotech. J. 40, No. 2, 388-402 (in French).

Laloui, L., Nuth, M. \& Vulliet, L. (2006). Experimental and numerical investigations of the behaviour of a heat exchanger pile. Int. J. Numer. Analyt. Methods Geomech. 30, No. 8, 763-781.

Lambe, T. (1973). Predictions in soil engineering. Géotechnique 23, No. 2, 151-202, http://dx.doi.org/10.1680/geot.1973.23.2.151.

Mattsson, N., Steinmann, G. \& Laloui, L. (2008). Advanced compact device for the in-situ determination of geothermal characteristics of soils. Energy and Buildings 40, No. 7, $1344-1352$.

McCartney, J. S. \& Murphy, K. D. (2012). Strain distributions in full-scale energy foundations. DFI J. 6, No. 2, 26-38.

Mimouni, T. \& Laloui, L. (2014). Towards a secure basis for the design of geothermal piles. Acta Geotechnica 9, No. 3, 355-366.

Mimouni, T. \& Laloui, L. (2015). Behaviour of a group of energy piles. Can. Geotech. J. 52, No. 12, 1913-1929.

Murphy, K. D., McCartney, J. S. \& Henry, K. S. (2014). Thermo-mechanical characterization of a full-scale energy foundation. In Proceedings: From soil behavior fundamentals to innovations in geotechnical engineering, Atlanta, GA, USA (eds M. Iskander, J. E. Garlange and M. H. Hussein), GSP 233, pp. 617-628. Reston, VA, USA: American Society of Civil Engineers (ASCE).

Murphy, K. D., McCartney, J. S. \& Henry, K. S. (2015). Evaluation of thermo-mechanical and thermal behavior of full-scale energy foundations. Acta Geotechnica 10, No. 2, 1-17.

Ng, C. W. W., Shi, C., Gunawan, A. \& Laloui, L. (2014). Centrifuge modelling of energy piles subjected to heating and cooling cycles in clay. Géotechnique Lett. 4, No. 4, 310-316.

Ng, C. W. W., Shi, C., Gunawan, A., Laloui, L. \& Liu, H. (2015). Centrifuge modelling of heating effects on energy pile performance in saturated sand. Can. Geotech. J. 52, No. 8, $1045-1057$.

Ng, C. W. W., Ma, Q. \& Gunawan, A. (2016). Horizontal stress change of energy piles subjected to thermal cycles in sand. Comput. Geotech. 78, 54-61.

Olgun, C. G., Ozudogru, T. Y. \& Arson, C. (2014). Thermo-mechanical radial expansion of heat exchanger piles and possible effects on contact pressures at pile-soil interface. Géotechnique Lett. 4, No. 3, 170-178.

Plum, R. L. \& Esrig, M. I. (1969). Some temperature effects on soil compressibility and pore water pressure, special report, vol. 103. Washington, DC, USA: Highway Research Board.

Poulos, H. G. \& Davis, E. H. (1980). Pile foundation analysis and design. New York, NY, USA: Rainbow-Bridge Book Company.

Randolph, M. \& Clancy, P. (1993). Efficient design of piled rafts. In Deep foundations on bored and auger piles, Ghent, Belgium (ed. W. F. Van Impe), pp. 119-130. Rotterdam, the Netherlands: Balkema.

Randolph, M. F. \& Wroth, C. P. (1978). Analysis of deformation of vertically loaded piles. J. Geotech. Engng Div. 104, No. 12, $1465-1488$.

Rotta Loria, A. F., Gunawan, A., Shi, C., Laloui, L. \& Ng, C. W. W. (2015). Numerical modelling of energy piles in saturated sand subjected to thermo-mechanical loads. Geomech. Energy Environ. 1, No. 1, 1-15. 
Saggu, R. \& Chakraborty, T. (2015). Cyclic thermo-mechanical analysis of energy piles in sand. Geotech. Geol. Engng 33, No. 1, $1-22$.

Salciarini, D., Ronchi, F., Cattoni, E. \& Tamagnini, C. (2015). Thermomechanical effects induced by energy piles operation in a small piled raft. Int. J. Geomech. 15, No. 2, 04014042.

Schmidt, B. (1966). Earth pressures at rest related to stress history. Can. Geotech. J. 3, No. 4, 239-242.

Stewart, M. A. \& McCartney, J. S. (2014). Centrifuge modeling of soil-structure interaction in energy foundations. J. Geotech. Geoenviron. Engng 140, No. 4, 04013044.

Suryatriyastuti, M., Mroueh, H. \& Burlon, S. (2012). Understanding the temperature-induced mechanical behaviour of energy pile foundations. Renewable and Sustainable Energy Rev. 16, No. 5, 3344-3354.

Suryatriyastuti, M., Burlon, S. \& Mroueh, H. (2016). On the understanding of cyclic interaction mechanisms in an energy pile group. Int. J. Numer. Analyt. Methods Geomech. 40, No. 1, 3-24.

Sutman, M., Olgun, C. \& Brettmann, T. (2015). Full-scale field testing of energy piles. In Proceedings of IFCEE 2015,
San Antonio, TX, USA (eds M. Iskander, M. T. Suleiman, J. B. Anderson and D. F. Laefer), vol. 1, pp. 1638-1647. Reston, VA, USA: American Society of Civil Engineers (ASCE).

Vega, A. \& McCartney, J. S. (2014). Cyclic heating effects on thermal volume change of silt. Environ. Geotech. 2, No. 5, 257-268, http://dx.doi.org/10.1680/envgeo.13.00022.

Vieira, A. \& Maranha, J. R. (2016). Thermoplastic analysis of a thermoactive pile in a normally consolidated clay. Int. J. Geomech., http://dx.doi.org/10.1061/(ASCE)GM.1943-5622. 0000666.

Wang, B., Bouazza, A., Singh, R. M., Haberfield, C., Barry-Macaulay, D. \& Baycan, S. (2014). Posttemperature effects on shaft capacity of a full-scale geothermal energy pile. J. Geotech. Geoenviron. Engng 141, No. 4, 04014125.

Yavari, N., Tang, A. M., Pereira, J. M. \& Hassen, G. (2014). Experimental study on the mechanical behaviour of a heat exchanger pile using physical modelling. Acta Geotechnica 9, No. 3, 385-398.

You, S., Cheng, X., Guo, H. \& Yao, Z. (2016). Experimental study on structural response of CFG energy piles. Appl. Thermal Engng 96, No. 1, 640-651. 